\begin{tabular}{|c|c|}
\hline Title & A ging of Passive Oxide on SU S304 Stainless Steel in a Sulfuric A cid Solution \\
\hline Author(s) & Ohtsuka, Toshiaki; Ueda, Mikito; A be, Masatoshi \\
\hline Citation & $\begin{array}{l}\text { J. Electrochemical Society, 163(8), C } 459-\text { C } 469 \\
\text { https://doi.org/10.1149/2.0721608jes }\end{array}$ \\
\hline Issue Date & 2016 \\
\hline Doc URL & http:/hdl.handle.net/2115/62190 \\
\hline Rights & $\begin{array}{l}\text { C The Electrochemical Society, Inc. 2016. A II rights reserved. Except as provided under U.S. copy right law, this work } \\
\text { may not be reproduced, resold, distributed, or modified without the express permission of The Electrochemical Society } \\
\text { (ECS). The archival version of this work was published in J. Electrochem. Soc. } 2016 \text { volume 163, issue 8, C 459-C } 469 \text {. }\end{array}$ \\
\hline Rights(URL) & http://creativecommons.org/icenses/by-nc-nd/4.0/ \\
\hline Type & article \\
\hline File Information & J. Electrochem. Soc.-2016-Ohtsuka C459-69.pdf \\
\hline
\end{tabular}

Instructions for use 


\title{
Aging of Passive Oxide on SUS304 Stainless Steel in a Sulfuric Acid Solution
}

\author{
Toshiaki Ohtsuka, ${ }^{\mathrm{z}}$ Mikito Ueda, ${ }^{*}$ and Masatoshi Abe ${ }^{\mathrm{a}}$ \\ Division of Materials Science and Engineering, Faculty of Engineering, Hokkaido University, Sapporo, \\ Hokkaido 060-8628, Japan
}

\begin{abstract}
The passive oxide film on SUS 304 stainless steel (SS) was studied in a $0.1 \mathrm{~mol} \mathrm{dm}^{-3}$ sulfuric acid solution as a function of passivation time. The passive oxide films were measured by ellipsometry and X-ray photoelectron spectroscopy (XPS). A Mott-Schottky plot of the film capacitance was employed to determine the donor density in the n-type semiconducting oxide film, and current measurements of the $\mathrm{Fe}^{3+} / \mathrm{Fe}^{2+}$ redox couple were employed to investigate the electronic transfer process on the passive oxide film. The passive oxide consists of $\mathrm{Cr}-\mathrm{Fe}-\mathrm{Ni}$ oxides in which enrichment of $\mathrm{Cr}$ to $57 \mathrm{~mol} \%$ occurs as the potential increases. During the aging of the passive oxide at $0.6 \mathrm{~V}$ vs. $\mathrm{Ag} / \mathrm{AgCl} / \mathrm{saturated} \mathrm{KCl}(\mathrm{SSC})$ for $43 \mathrm{ks}$, the current decreased from $30 \mu \mathrm{A} \mathrm{cm} \mathrm{cm}^{-2}$ at $10 \mathrm{~s}$ to $0.025 \mu \mathrm{A} \mathrm{cm}{ }^{-2}$ at $43 \mathrm{ks}$, and the $\mathrm{Cr}$ ratio in the oxide increased from 49 to $57 \mathrm{~mol} \%$ with an increase in the $\mathrm{O}^{2-}$ ratio. Notably, the film thickness remained nearly constant at $1.3 \mathrm{~nm}$ during the aging process. Enrichment of the $\mathrm{Cr}$ content resulted in a decrease in the donor density of the n-type semiconducting passive oxide and the inhibition of electronic charge transfer from/to the $\mathrm{Fe}^{3+} / \mathrm{Fe}^{2+}$ redox couple in the electrolyte.

(C) The Author(s) 2016. Published by ECS. This is an open access article distributed under the terms of the Creative Commons Attribution Non-Commercial No Derivatives 4.0 License (CC BY-NC-ND, http://creativecommons.org/licenses/by-nc-nd/4.0/), which permits non-commercial reuse, distribution, and reproduction in any medium, provided the original work is not changed in any way and is properly cited. For permission for commercial reuse, please email: oa@electrochem.org. [DOI: 10.1149/2.0721608jes] All rights reserved.
\end{abstract}

Manuscript submitted December 2, 2015; revised manuscript received May 16, 2016. Published June 2, 2016.

The corrosion resistance of stainless steel is the result of surface passive films enriched in chromium. The passive oxide film on conventional austenitic stainless steel (SS) SUS304 has been investigated with a focus on its composition, ${ }^{1-6}$ thickness ${ }^{7-9}$ and semiconducting properties. ${ }^{5,6,10-20}$ For the oxide formed in an acidic aqueous solution, the chromium oxide component was enriched to a ratio of approximately $50-60 \mathrm{~mol} \%$ in passive oxide in an acidic aqueous solution. ${ }^{1-3}$ Its thickness was estimated by ellipsometry to be $1-2 \mathrm{~nm} .{ }^{8,20}$ In neutral and slightly alkaline solutions, the passive oxide consists of an inner chromium-rich oxide layer and an outer iron-rich oxide layer. ${ }^{4-6}$ The semiconducting properties of passive oxides ${ }^{5,6,10-20}$ has been estimated from a Mott-Schottky plot of the capacitance data and photoelectrochemical measurements. The Mott-Schottky plot in the potential range, in which little reduction of the film occurs, indicated that the passive oxide had an n-type semiconducting property. ${ }^{6,10,13,16,19,21}$ However, the results of photo-electrochemical measurement indicated that the passive oxide had both n-type and p-type semiconducting properties. ${ }^{5,17,18}$

Because there are no in situ techniques available to determine the composition of the thin passive oxide on 304 SS, ex-situ spectroscopies performed in vacuum, such as X-ray photoelectron spectroscopy (XPS) $)^{1-4,6}$ and Auger electron spectroscopy (AES), ${ }^{4,5}$ have been used to obtain this information. Additionally, the film composition and structure were determined using simulations involving photoelectron signals and the attenuation of these signals of the ionic and metallic species. For the anodic passive oxide on 304 SS and on $\mathrm{Fe}-\mathrm{Cr}$ alloys in sulfuric acid solutions, quantitative simulation was reported by various authors by using XPS ${ }^{3,21,23-26}$ and AES. ${ }^{22}$ Asami et al. ${ }^{21}$ and Kirchheim et al. ${ }^{23}$ reported a relation between the compositions of the oxide film and the substrate of $\mathrm{Fe}-\mathrm{Cr}$ alloys at various $\mathrm{Cr}$ concentrations. They found that enrichment of $\mathrm{Cr}$ in the passive oxide in a sulfuric acid solution, for example, enriched $\mathrm{Cr}$ in the passive oxide film to approximately $60 \mathrm{~mol} \%$ on $\mathrm{Fe}-18 \mathrm{~mol} \% \mathrm{Cr}$ alloy. In addition, Marcus et al. reported the enrichment of $\mathrm{Cr}$ in the passive oxide on $\mathrm{Fe}-22 \mathrm{Cr},{ }^{25,26} \mathrm{Fe}-17 \mathrm{Cr},{ }^{27}$ and $\mathrm{Fe}-18 \mathrm{Cr}-13 \mathrm{Ni}$, ${ }^{3}$ and an additional enrichment of $\mathrm{Cr}$ on the $\mathrm{Fe}-\mathrm{Cr}$ alloy surface underneath the passive oxide. $^{24,25}$ The enrichment of $\mathrm{Cr}$ in the passive oxide film has been explained by selective dissolution of $\mathrm{Fe}$ in the acidic solution. ${ }^{24,26} \mathrm{In}$

*Electrochemical Society Member.

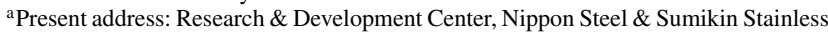
Steel Corp., Hikari, Yamaguchi 743-8550, Japan.

${ }^{\text {z} E-m a i l: ~ o h t s u k a @ e n g . h o k u d a i . a c . j p ~}$ connection with the $\mathrm{Cr}$ enrichment in the oxide film, the critical $\mathrm{Cr}$ ratio of the substrate to induce passivation in acidic solution has been elucidated by graph theory ${ }^{27,28}$ and a percolation model. ${ }^{29}$

Previously, we reported the thickness and semiconducting properties of the passive oxide film on SUS304 SS in a $0.1 \mathrm{~mol} \mathrm{dm}^{-3}$ (M) sulfuric acid solution using ellipsometry, potential modulation reflectance (PMR), and capacitance measurements. ${ }^{20}$ The thickness of the film was in the range of $1-1.3 \mathrm{~nm}$ and increased as the potential increased in the passive region. In addition, a further increase in the transpassive region to $1.8 \mathrm{~nm}$ at $0.9 \mathrm{~V}$ vs. $\mathrm{Ag} / \mathrm{AgCl} /$ saturated $\mathrm{KCl}$ (SSC) was observed. From the PMR results, the optical absorption edge (i.e., the bandgap energy) was found to be approximately $2.4 \mathrm{eV}$, and from the Mott-Schottky plot of the capacitance estimated by AC impedance, the donor density of the n-type semiconducting passive oxide was found to be approximately $8 \times 10^{20} \mathrm{~cm}^{-3}$.

In this study, we measured the $\mathrm{Cr}$ enrichment of the passive oxide on SUS 304 SS using XPS as a function of the potential and time period under constant potential oxidation. Additionally, the film thickness and semiconducting properties were measured as a function of time using ellipsometry and measurements of the capacitance and $\mathrm{Fe}^{3+} / \mathrm{Fe}^{2+}$ reduction-oxidation (redox) current, respectively. During the aging of the passive oxide, Kirchheim et al. measured the $\mathrm{Cr}$ enrichment in the passive oxide on $\mathrm{Fe}-18 \mathrm{Cr}$ alloy in a $0.5 \mathrm{M} \mathrm{H}_{2} \mathrm{SO}_{4}$ solution by XPS and found a gradual enrichment of $\mathrm{Cr}$ from $45 \mathrm{~mol} \%$ at $20 \mathrm{~s}$ to $67 \mathrm{~mol} \%$ at $2 \times 10^{4} \mathrm{~s}$ at constant potential in the passive region. ${ }^{24}$ In the present study, we also observed a gradual enrichment of $\mathrm{Cr}$ in the oxide film on SUS304 SS under constant potential control. Further, we compared the enrichment of $\mathrm{Cr}$ with the change in thickness and semiconducting properties of the oxide film during its aging.

\section{Experimental}

The composition of SUS304 stainless steel (SS) used in this study was $18.29 \mathrm{wt} \% \mathrm{Cr}$ and $8.75 \mathrm{wt} \% \mathrm{Ni}$ with minor components consisting of $0.066 \mathrm{wt} \% \mathrm{C}, 0.58 \mathrm{wt} \% \mathrm{Si}, 0.029 \mathrm{wt} \% \mathrm{P}, 0.002 \mathrm{wt} \% \mathrm{~S}, 0.82$ wt $\% \mathrm{Mn}$, and 0.14 wt $\%$ Mo. The SS sheet was purchased from the Japan Stainless Steel Association. The 2-mm-thick SS sheet was cut into discs with a 15-mm diameter for the electrochemical and XPS measurements and a 24-mm diameter for ellipsometry. One side of the disc was polished by an alumina abrasive with a $0.05-\mu \mathrm{m}$ diameter to produce a mirror-like surface. The disc was fixed by a Teflon spacer or a rubber O-ring into an electrode holder made of Teflon. 
The polished side was exposed to an electrolyte solution for the electrochemical measurements. The exposure area was $0.785 \mathrm{~cm}^{2}$ for the electrochemical and XPS measurements and $1.130 \mathrm{~cm}^{2}$ for the ellipsometry measurements. The other side of the disc was connected to a brass disc in the Teflon holder and then to a potentiostat using a copper lead.

The Hokuto Denko HZ-5000 and H-500 potentiostats were used for the electrochemical control. A glass cell with a $100 \mathrm{~mL}$ solution volume was used for the electrochemical measurements. A platinum sheet was used as a counter electrode and the reference electrode was $\mathrm{Ag} / \mathrm{AgCl} /$ saturated $\mathrm{KCl}$ (SSC) on a Luggin glass capillary. The 304 $\mathrm{SS}$ electrode was first reduced at $-0.40 \mathrm{~V}$ vs. SSC for $1.8 \mathrm{ks}$ in a $0.1 \mathrm{~mol}$ $\mathrm{dm}^{-3}$ (M) $\mathrm{H}_{2} \mathrm{SO}_{4}$ aqueous solution to remove air-formed oxide film on the polished surface. It was then passivated under potentiostatic control in a $0.1 \mathrm{M} \mathrm{H}_{2} \mathrm{SO}_{4}$ solution. The redox current of $\mathrm{Fe}^{3+} / \mathrm{Fe}^{2+}$ on the passivated $304 \mathrm{SS}$ was measured in an acidic solution consisting of $0.1 \mathrm{M} \mathrm{H}_{2} \mathrm{SO}_{4}$ containing $0.05 \mathrm{M}\left(\mathrm{NH}_{4}\right)_{2} \mathrm{Fe}\left(\mathrm{SO}_{4}\right)_{2}$ and $0.05 \mathrm{M}$ $\mathrm{NH}_{4} \mathrm{Fe}\left(\mathrm{SO}_{4}\right)_{2}$. The electrolyte was deaerated by bubbling pure $\mathrm{N}_{2}$ gas prior to use and the electrochemical measurement was performed under pure $\mathrm{N}_{2}$ gas passing through the electrochemical cell. All of the solutions were prepared using Milli-Q pure water and analytical grade reagents.

The AC impedance of the passivated SS was measured by a frequency response analyzer (NF Design Circuit 5020) connected to a potentiostat constructed in our laboratory. For the $\mathrm{AC}$ impedance, the AC amplitude at $0.01 \mathrm{~V}_{\mathrm{rms}}$ was superimposed on the DC potential of the potentiostat.

To estimate the composition of the passive oxide on 304 SS, Xray photoelectron spectroscopy (XPS) was employed using a JEOL JPS-9200. After passivation in a $0.1 \mathrm{M} \mathrm{H}_{2} \mathrm{SO}_{4}$ solution, the SS disc was removed from the Teflon holder, washed with pure water in the atmosphere, dried by $\mathrm{N}_{2}$ gas, and stored in a dry box filled with $\mathrm{N}_{2}$ gas. The SS disc was then removed from the dry box and quickly inserted into the XPS apparatus. The XPS measurement employed a $\mathrm{MgK} \alpha \mathrm{X}$-ray source at $1253.6 \mathrm{eV}$. The calibration of the binding energy of the photoelectron was performed using the Au4f7/2 signal with a binding energy of $84.00 \mathrm{eV}$. To check the reproducibility of the XPS measurement, we measured the passive oxides formed at $0.6 \mathrm{~V}$ vs. SSC for $3.6 \mathrm{ks}$ three times. We could estimated the cationic composition in molar ratio in the oxide, for example, $\mathrm{X}(\mathrm{Cr})=0.58$ \pm 0.03 .

The film thickness was measured by in-situ ellipsometry using a rotating analyzer automated ellipsometer with an optical arrangement that consisted of a polarizer (P)-reflection sample (S)-rotating analyzer (A). Light from an output-stabilized He-Ne laser at a wavelength of $632.8 \mathrm{~nm}$ was used for the measurement, and the incidence angle to the reflected electrode was $\phi_{1}=60.0 \mathrm{deg}$. For the P-S-A arrangement, the ellipsometry parameters (i.e., $\tan \Psi$ (relative amplitude ratio of p-polarized light to s-polarized light) and $\Delta$ (relative phase retardation between $\mathrm{p}$ - and s-polarized light)) were estimated from the in-phase component $(\alpha)$ and out-of-phase component $(\beta)$ of the reflected light intensity relative to two times the azimuth of the rotating analyzer $(A)$.

$$
R=R_{\mathrm{DC}}\{1+\alpha \cos (2 A)+\beta \sin (2 A)\}
$$

$$
\tan \psi \exp \mathrm{j} \Delta=\tan P\left[(1+\alpha) /\left\{\beta \pm \mathrm{j}\left(1-\alpha^{2}-\beta^{2}\right)^{1 / 2}\right\}\right]
$$

where $R_{\mathrm{DC}}$ is a DC component of the reflectance and $P$ is the fixed azimuth of the polarizer. The $\alpha$ and $\beta$ values were measured using a two-phase lock-in amplifier. The ellipsometer was constructed in our laboratory. The $\alpha, \beta$ and $R_{\mathrm{DC}}$ data were typically stored in 1 -s intervals in a data logger with the electrochemical data (i.e., potential and current). $\Psi, \Delta$ and the reflectance change $\left(\Delta R / \mathrm{R}_{0}\right)$ were calculated from the stored values using a computer program. The reflectance change was defined as:

$$
\Delta R / R_{0}=\left[R_{\mathrm{DC}}(\mathrm{f})-R_{\mathrm{DC}}(0)\right] / R_{\mathrm{DC}}(0)
$$

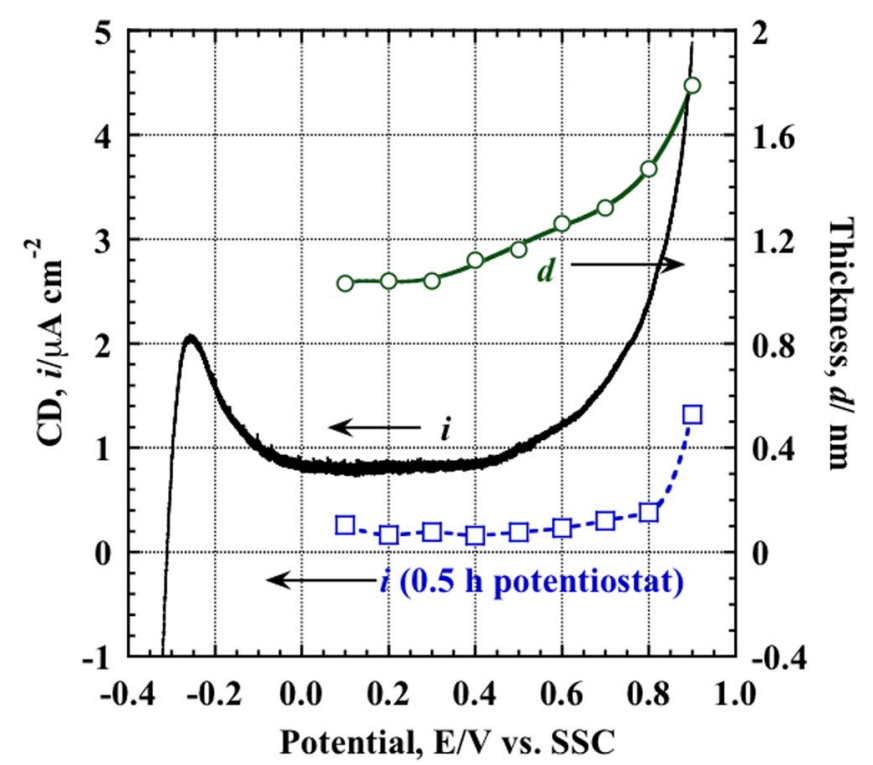

Figure 1. Potential-current curve of SUS304 SS during a potential sweep from $-0.4 \mathrm{~V}$ vs. SSC to $0.9 \mathrm{~V}$ at a sweep rate of $3 \times 10^{-4} \mathrm{~V} \mathrm{~s}^{-1}$ in a $0.1 \mathrm{M}$ $\mathrm{H}_{2} \mathrm{SO}_{4}$ solution and during a stepwise potential increase with a step of $0.1 \mathrm{~V}$

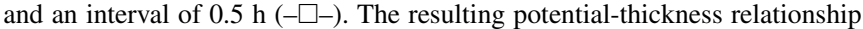
was measured during the stepwise potential increase $(-\circ-) .^{21}$

where $R_{\mathrm{DC}}(\mathrm{f})$ is the DC reflectance of the SS surface covered by the passive oxide and $R_{\mathrm{DC}}(0)$ is the DC reflectance of the reduced SS surface at $-0.4 \mathrm{~V}$.

\section{Results}

Current-potential relationship.- The potentiodynamic polarization curve for $304 \mathrm{SS}$ in a $0.1 \mathrm{M} \mathrm{H}_{2} \mathrm{SO}_{4}$ solution is shown in Fig. 1. The measurement was performed from $-0.35 \mathrm{~V}$ vs. SSC to $0.9 \mathrm{~V}$ at a potential sweep rate of $3 \times 10^{-4} \mathrm{~V} \mathrm{~s}^{-1}$ after cathodic reduction at $-0.4 \mathrm{~V}$ for $1.8 \mathrm{ks}$. A small anodic peak appeared at $-0.26 \mathrm{~V}$, and then the passive region in which the $\mathrm{CD}$ was constant at $0.8 \mu \mathrm{A} \mathrm{cm}^{-2}$ began at $0.0 \mathrm{~V}$. The CD gradually increased at potentials higher than $0.45 \mathrm{~V}$. In Fig. 1, the thickness and CD are also plotted, which reported in a previous paper. ${ }^{21}$ The thickness was measured by a step-wise increase in the potential in the passive region with a step interval of $30 \mathrm{~min}$ using ellipsometry, and the $\mathrm{CD}$ was recorded at $30 \mathrm{~min}$ intervals at the individual potentials. The CD increased from $0.45 \mathrm{~V}$ on the potentiodynamic polarization curve; however, the $\mathrm{CD}$ on the potentiostatic polarization curve began to increase at $0.85 \mathrm{~V}$. The transpassive dissolution of $\mathrm{CrO}_{4}{ }^{2-}$ is assumed to begin at the potential of $0.85 \mathrm{~V}^{20,23}$ and the passive region is in the range from $-0.5 \mathrm{~V}$ to $0.8 \mathrm{~V} .^{20,23}$

Composition of the passive oxide using XPS as a function of potential.-The composition of the passive oxide formed at various potentials was estimated using XPS. Figure 2 shows examples of the XPS spectra of $\mathrm{Fe} 2 \mathrm{p} 3 / 2, \mathrm{Cr} 2 \mathrm{p} 3 / 2, \mathrm{Ni} 2 \mathrm{p} 3 / 2$, and $\mathrm{O} 1 \mathrm{~s}$ of the reduced $\mathrm{SS}$ at $-0.4 \mathrm{~V}$ for $1.8 \mathrm{ks}$ and the passivated $\mathrm{SS}$ at potential ranging from $-0.1 \mathrm{~V}$ to $1.1 \mathrm{~V}$ for $3.6 \mathrm{ks}$. The reduced surface at $-0.4 \mathrm{~V}$ was covered by an air-formed oxide film caused by exposure to the atmosphere following reduction. On the spectra in Fig. 2, the background was compensated by a linear function. The photoelectrons were collected in the direction normal to the specimen surface. The dashed lines in Figs. 2A, 2B, and 2C indicate the peak positions of the metallic elements (i.e., $\mathrm{Fe}, \mathrm{Cr}$, and $\mathrm{Ni}$ ). The peak positions of the metal cations in the passive oxide are located at higher binding energies. The O1s spectra shown in Fig. 2D can be deconvoluted into three peaks, which correspond to oxygen ions in $\mathrm{O}^{2-}, \mathrm{OH}^{-}$, and $\mathrm{H}_{2} \mathrm{O}$.

The $2 \mathrm{p} 3 / 2$ spectra of the three metals can be deconvoluted into metallic elements in the substrate and cationic elements in the oxide. 
(A)

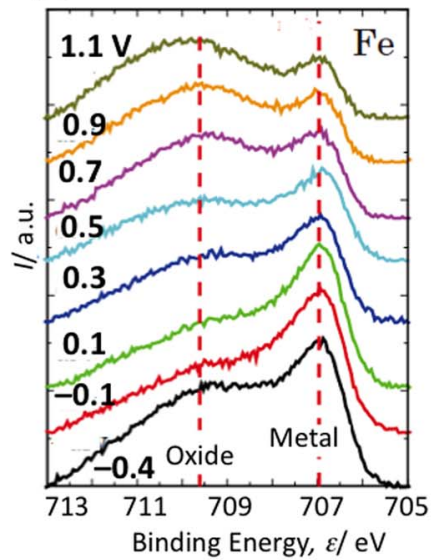

(C)

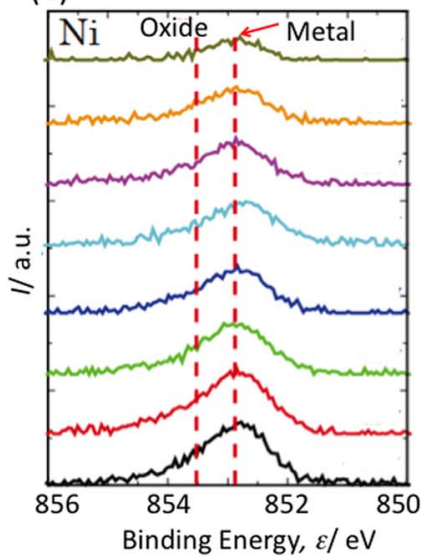

(B)

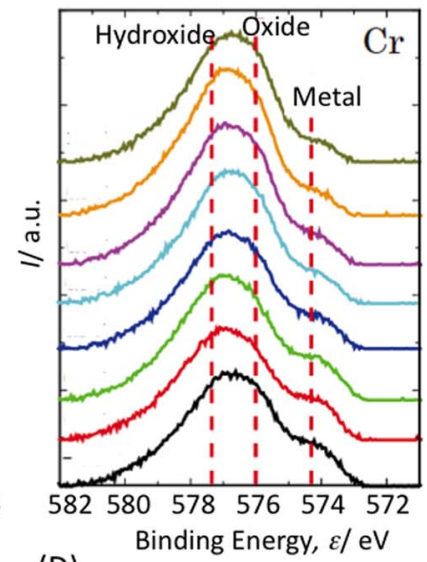

(D)

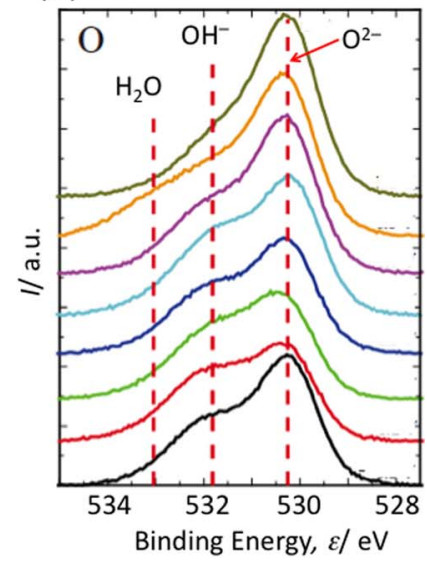

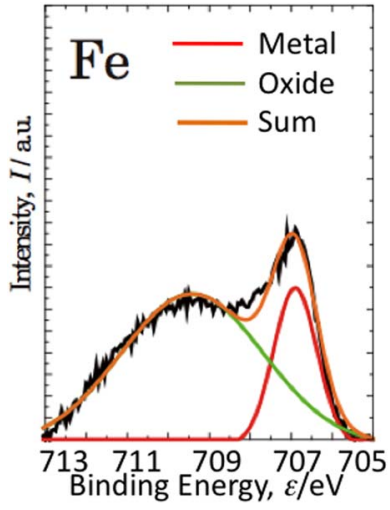
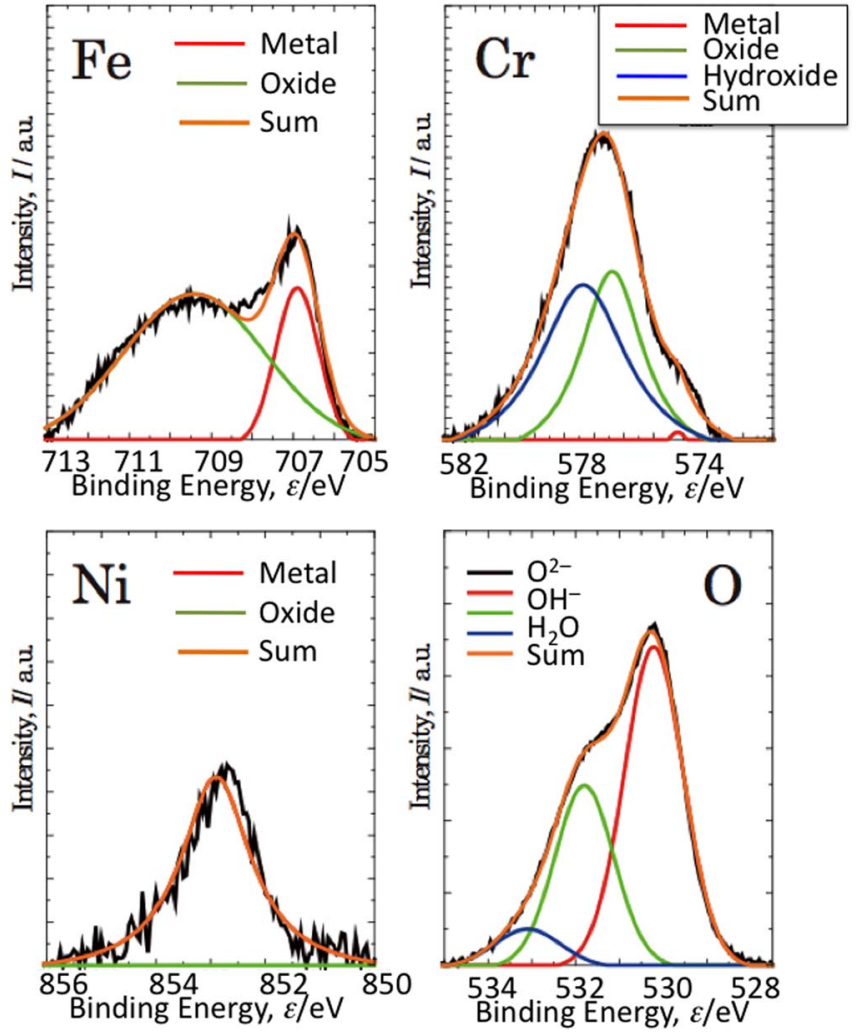

Figure 3. Examples of the deconvolution of the spectra of $\mathrm{Fe}, \mathrm{Cr}$, and $\mathrm{Ni}$ to oxide and metallic components and of the spectrum of $\mathrm{O}$ to $\mathrm{O}^{2-}, \mathrm{OH}^{-}$, and $\mathrm{H}_{2} \mathrm{O}$. The data correspond to the spectra of passivated SS at $0.1 \mathrm{~V}$ for $1 \mathrm{~h}$.

Figure 2. XPS spectra of (A) Fe2p3/2, (B) Cr2p3/2, (C) Ni2p3/2, and (D) $\mathrm{O} 1 \mathrm{~s}$ of the reduced and passivated type $304 \mathrm{SS}$ at various potentials for $1 \mathrm{~h}$ in a $0.1 \mathrm{M} \mathrm{H}_{2} \mathrm{SO}_{4}$ solution. The spectra were plotted from the bottom at $-0.4 \mathrm{~V}$, $-0.1 \mathrm{~V}, 0.1 \mathrm{~V}, 0.3 \mathrm{~V}, 0.5 \mathrm{~V}, 0.7 \mathrm{~V}, 0.9 \mathrm{~V}$, and $1.1 \mathrm{~V}$ vs. SSC.

Typical examples of the deconvolution of the spectra are shown in Fig. 3 , in which the data refer to the spectra passivated at $0.6 \mathrm{~V}$ for $1 \mathrm{~h}$. For the deconvolution of the signals of $\mathrm{Fe}, \mathrm{Cr}$, and $\mathrm{Ni}$, we optimized the peak positions, $P_{\mathrm{BE}}$ of the metallic elements, and metal ions in the oxide with the assumption of constant FWHM (full width at half maximum). Likewise, the oxygen signal was deconvoluted in similar manner to the metal signals by optimizing the peak energies with constant values of $F W H M$. The data used for the deconvolution are shown in Table I. The values for the metallic elements were obtained by the XPS measurement of $304 \mathrm{SS}$ after $30 \mathrm{~min}^{+} \mathrm{Ar}^{+}$sputtering of the polished surface. The energy peaks of the metallic elements agree with those in the literature in a $0.1 \mathrm{eV}$ range. ${ }^{24,31,34,35}$ For the oxide elements, we assumed a single chemical state for $\mathrm{Fe}$ and $\mathrm{Ni}$ and two $\mathrm{Cr}$ states (i.e., $\mathrm{Cr}_{2} \mathrm{O}_{3}$ and $\left.\mathrm{Cr}(\mathrm{OH})_{3}\right){ }^{21,23,31-33}$

The relatively large $F W H M$ of oxidized Fe indicates that the spectra include several states of $\mathrm{Fe}$ (II) or Fe(III)-oxide, Fe(III)-oxyhydroxide, and Fe(III)-hydroxide. Although many authors have deconvoluted the oxidized Fe spectra into several peaks corresponding to the individual chemical states, ${ }^{1-3,21,23-26}$ we treated the oxidized $\mathrm{Fe}$ as a single

chemical state because the peak positions of the reported individual compounds differed between publications..$^{21,23-26,33,34}$ In the deconvolution, the peak energies were assumed to be constant for the quantitative analysis and the deconvolution process was very likely to introduce artificial error because of the selection of the peak positions. In this study we emphasized the quantitative ratio of the metal ions in the oxide rather than the detailed states of individual metallic ions. Thus, we estimated the relative intensities of the XPS peaks for the metal oxide from the assumption that it consists of a single state with a relatively large $F W H M$. For $\mathrm{Ni}$, because the XPS signal of the $\mathrm{Ni}$ ion in the oxide was much weaker than that of the metallic element, we could not simulate the signal shape in detail. We assumed that the $\mathrm{Ni}$ ions were $\mathrm{Ni}^{2+}$ in $\mathrm{NiO}{ }^{33}$ For $\mathrm{Cr}$ oxide, we estimated the relative intensity to be one compound (Cr-oxide) containing both $\mathrm{Cr}_{2} \mathrm{O}_{3}$ and $\mathrm{Cr}(\mathrm{OH})_{3}$. From the relative intensity of the three metallic cations, quantitative analysis was performed to estimate the molar ratio of each ionic element (i.e., $\mathrm{Fe}, \mathrm{Cr}$, and $\mathrm{Ni}$ ) in the passive oxide. The calibration of the concentration ratio of the metallic cations was achieved using the relative intensity of the XPS spectra corresponding to the metallic elements from the SS substrate. To estimate the relative intensity among the three metals, the spectra of the polished SS were recorded after Ar ion sputtering for 10 and 30 min at which the oxygen signal completely disappeared. After $10 \mathrm{~min}$ of sputtering, the intensities of the three metals changed very little. The relative intensities $\left(I_{\mathrm{Fe}}, I_{\mathrm{Cr}}\right.$,

Table I. Peak position $\left(P_{\mathrm{BE}}\right)$ and half width at half maximum $(F W H M)$ of $\mathrm{Fe} 2 \mathrm{p} 3 / 2, \mathrm{Cr} 2 \mathrm{p} 3 / 2, \mathrm{Ni2p} 3 / 2$, and $\mathrm{O1s}$ for the calculation of intensities.

\begin{tabular}{|c|c|c|c|c|c|c|c|c|c|c|}
\hline & \multicolumn{2}{|c|}{$\mathrm{Fe} 2 \mathrm{p} 3 / 2$} & \multicolumn{3}{|c|}{$\mathrm{Cr} 2 \mathrm{p} 3 / 2$} & \multicolumn{2}{|c|}{$\mathrm{Ni} 2 \mathrm{p} 3 / 2$} & \multicolumn{3}{|c|}{$\mathrm{O} 1 \mathrm{~s}$} \\
\hline & $\mathrm{Fe}$ (metal) & Fe-oxide & $\mathrm{Cr}($ metal $)$ & $\mathrm{Cr}(\mathrm{OH})_{3}$ & $\mathrm{Cr}_{2} \mathrm{O}_{3}$ & $\mathrm{Ni}($ metal) & $\mathrm{NiO}$ & $\mathrm{O}^{2-}$ & $\mathrm{OH}^{-}$ & $\mathrm{H}_{2} \mathrm{O}$ \\
\hline$P_{\mathrm{BE}} / \mathrm{eV}$ & $706.9 \pm 0.1$ & $709.5 \pm 0.3$ & $574.2 \pm 0.1$ & $577.4 \pm 0.1$ & $576.4 \pm 0.1$ & $852.8 \pm 0.1$ & $853.6 \pm 0.2$ & $530.2 \pm 0.1$ & $5301.8 \pm 0.1$ & $\begin{array}{c}533.2 \pm 0.2 \\
1.8\end{array}$ \\
\hline
\end{tabular}


(A)
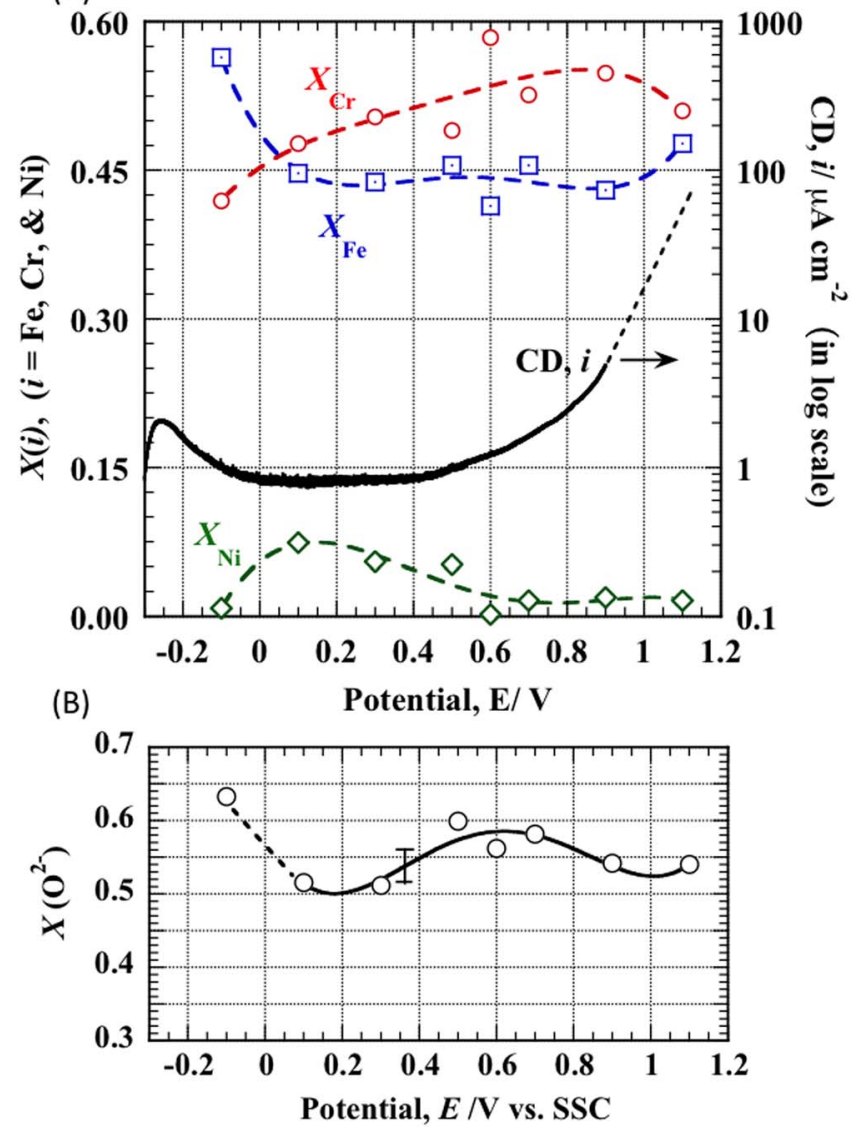

Figure 4. (A) Molar ratios of the $\mathrm{Fe}, \mathrm{Cr}$, and $\mathrm{Ni}$ cations and (B) molar ratio of $\mathrm{O}^{2-}$ to $\left(\mathrm{O}^{2-}+\mathrm{OH}^{-}\right)$in the passive oxide formed on SUS304 SS at various potentials in a $0.1 \mathrm{M} \mathrm{H}_{2} \mathrm{SO}_{4}$ solution. In Fig. (A), the log of $\mathrm{CD}$ as a function of potential was plotted with the data reported in Fig. 1.

and $I_{\mathrm{Ni}}$ ) of the XPS peaks of the three metals from the SS substrate after 10 min of sputtering were compared with the real molar ratios $\left(\mathrm{x}_{\mathrm{Fe}}, \mathrm{x}_{\mathrm{Cr}}\right.$, and $\left.\mathrm{x}_{\mathrm{Ni}}\right)$ of the substrate:

$$
a_{\mathrm{Fe}} I_{\mathrm{Fe}}: a_{\mathrm{Cr}} I_{\mathrm{Cr}}: a_{\mathrm{Ni}} I_{\mathrm{Ni}}=\mathrm{x}_{\mathrm{Fe}}: \mathrm{x}_{\mathrm{Cr}}: \mathrm{x}_{\mathrm{Ni}}
$$

The calibration factors $\left(a_{\mathrm{Fe}}, a_{\mathrm{Cr}}\right.$, and $\left.a_{\mathrm{Ni}}\right)$ were then determined. The factors were used to determine the ratios of the three cations (i.e., $\mathrm{Cr}$, $\mathrm{Fe}$, and $\mathrm{Ni}$ ions) in the oxide film in the following section.

The molar ratios of the three cations in the passive oxide are shown in Fig. 4A as a function of potential. The $\mathrm{Cr}$ ratio was 0.47 at $0.1 \mathrm{~V}$ and gradually increased with potential to 0.58 at $0.6 \mathrm{~V}$. At higher potentials in the transpassive region at $1.1 \mathrm{~V}$, the $\mathrm{Cr}$ ratio decreased because of $\mathrm{Cr}(\mathrm{VI})$ dissolution. The Ni ratio was approximately 0.07 at $0.1 \mathrm{~V}$, and this ratio decrease to 0.02 as the potential increased to more than $0.6 \mathrm{~V}$. On the passive oxide formed on an $\mathrm{Fe}-18 \mathrm{Cr}-13 \mathrm{Ni}$ single crystal at 0.5 $\mathrm{V}$ vs. SHE for $2 \mathrm{~h}$ in a $0.5 \mathrm{M} \mathrm{H}_{2} \mathrm{SO}_{4}$ solution, Maurice et al. ${ }^{3}$ reported the results from a simulation that $\mathrm{Cr}$ oxide was enriched at $62 \mathrm{~mol} \%$ with the assumption of a bi-layer model consisting of an outer $\mathrm{Cr}$ hydroxide layer and an inner $\mathrm{Fe}-\mathrm{Cr}$ oxide layer. They also reported that $\mathrm{Cr}$ oxide was enriched at $55 \mathrm{~mol} \%$ in the passive oxide formed on an $\mathrm{Fe}-17 \mathrm{Cr}$ single crystal at $0.39 \mathrm{~V}$ vs. SHE for $1 \mathrm{~h}$ in a $0.02 \mathrm{M} \mathrm{NaCl}$ solution ${ }^{26}$ and at $90 \mathrm{~mol} \%$ in the passive oxide on an $\mathrm{Fe}-22 \mathrm{Cr}$ single oxide at $0.50 \mathrm{~V}$ vs. SHE for $2 \mathrm{~h}$ in a $0.5 \mathrm{M} \mathrm{H}_{2} \mathrm{SO}_{4}$ solution. ${ }^{24}$ The $\mathrm{Cr}$ enrichment in the passive oxide film was also reported on $\mathrm{Fe}-\mathrm{Cr}$ alloys in an acidic $\mathrm{H}_{2} \mathrm{SO}_{4}$ solution by Asami et al. ${ }^{21}$ and Kirchheim et al. ${ }^{23}$ For the Fe-18Cr alloy, they found $62-65 \mathrm{~mol} \%$ enrichment of $\mathrm{Cr}$ oxide in the passive oxide. The enrichment of $\mathrm{Cr}$ in the present study appears to be slightly smaller than that in the XPS results reported by these other authors. ${ }^{21,23}$ Nevertheless, because the present results were
(A)

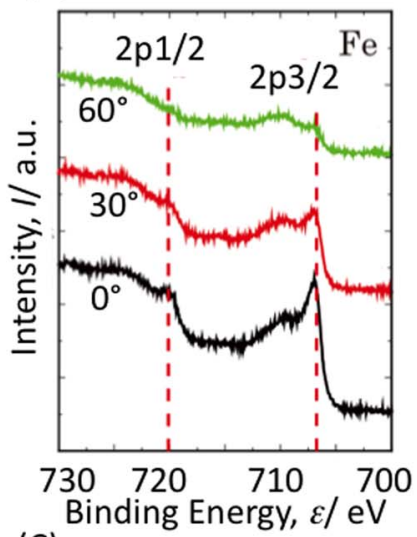
(C)

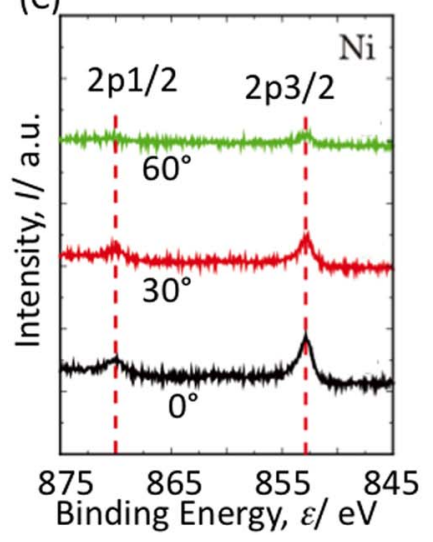

(B)

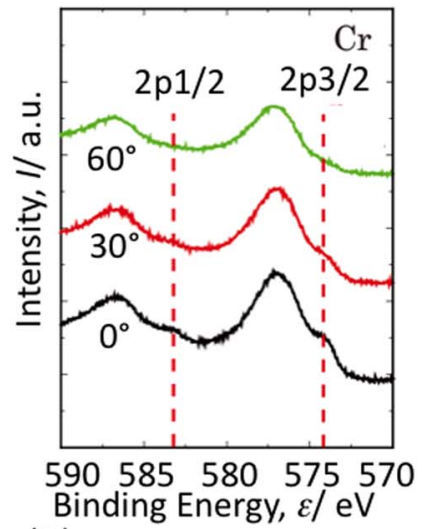

(D)

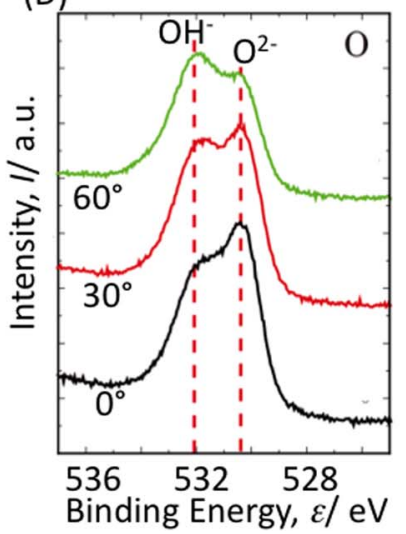

Figure 5. XPS spectra of (A) $\mathrm{Fe},(\mathrm{B}) \mathrm{Cr}$, (C) $\mathrm{Ni}$, and (D) $\mathrm{O}$ of the passive oxide on SUS304 SS formed at $0.1 \mathrm{~V}$ vs. SSC for $1 \mathrm{~h}$ as a function of detection angle.

estimated from the apparent intensities without any model simulation, the small difference from the molar fraction of $\mathrm{Cr}$ calculated from the model simulation by the other authors is reasonable.

In Fig. 4B, the ratio of $\mathrm{O}^{2-}$ to total oxygen (i.e., $\mathrm{O}^{2-}+\mathrm{OH}^{-}$) in the passive oxide was plotted as a function of potential. Because the intensity of the $\mathrm{H}_{2} \mathrm{O}$ spectrum in the oxide was relatively small, its contribution was omitted. The molar ratio of $\mathrm{O}^{2-}$ reached 0.57 in a passive potential region of $0.5-0.7 \mathrm{~V}$. In the initial passive and transpassive regions, the ratio was about 0.5 .

The elemental profile as a function of depth was estimated by multiple-angle detection where the photoelectrons were detected as a function of the angle $(\theta)$ between the spectroscopic analyzer of the photoelectron and the normal to the specimen surface. The analytical depth, which is estimated by a distance in the perpendicular direction to the surface, was proportional to $\cos \theta$ :

$$
\mathrm{D}(\theta)=D_{0} \cos \theta
$$

where $D(\theta)$ is the analytical depth measured at the angle $\theta$ and $D_{0}$ is the mean free path of a photoelectron with a given energy in the solid phase. From Eq. 5, the analytical depth is smaller with larger angles, and therefore, the molar ratios estimated from the XPS signals at larger angles represent the ratios in the outer portion of the passive oxide. ${ }^{3,24}$

The results by the multiple-angle detection are given in Fig. 5 . Here, the XPS spectra of the SS passivated at $0.1 \mathrm{~V}$ for $3.6 \mathrm{ks}$ were measured at three detection angles (i.e., 0, 30, and $60 \mathrm{deg}$ ). In Figs. $5 \mathrm{~A}, 5 \mathrm{~B}$, and $5 \mathrm{C}$, the peak intensities of the metallic elements in the substrate, denoted by the dashed lines, are seen to decrease at larger angles. This occurs because the signals from the metallic elements in the substrate are attenuated more in the oxide film by a smaller analytical depth at larger angles, according to Eq. 5. In Fig. 5D, the 


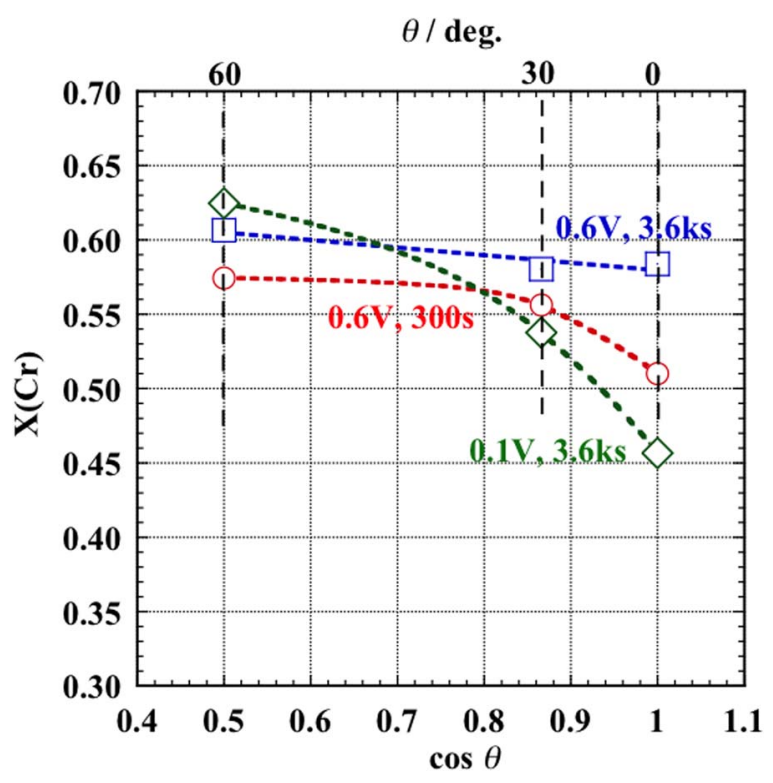

Figure 6. Dependence of the $\mathrm{Cr}$ ratio on the angle of detection $(\theta)$ of photoelectrons for the passive oxide formed on SUS304 SS at $0.1 \mathrm{~V}$ for $3.6 \mathrm{ks}$, at $0.6 \mathrm{~V}$ for $300 \mathrm{~s}$, and at $0.6 \mathrm{~V}$ for $3.6 \mathrm{ks}$ in $0.1 \mathrm{M} \mathrm{H}_{2} \mathrm{SO}_{4}$ solutions.

$\mathrm{OH}^{-}$signal relative to the $\mathrm{O}^{2-}$ signal increased with a larger detection angle, indicating that $\mathrm{OH}^{-}$preferentially distributes to the outer portion of the oxide film and $\mathrm{O}^{2-}$ mainly exists in the inner portion.

Figure 6 shows the average molar ratio of $\mathrm{Cr}$ in the passive oxide estimated at three detection angles $(\theta)$ as a function of $\cos \theta$. From the increase in the $\mathrm{Cr}$ ratio with a smaller $\cos \theta$, it is found that more $\mathrm{Cr}$ enrichment occurs at the outer portion of the passive oxide. Because greater distribution of $\mathrm{OH}^{-}$was observed at the more outer portion in Fig. 5D, it is concluded that the outer oxide film contains more $\mathrm{Cr}$ hydroxide and the inner oxide film contains more $\mathrm{Cr}$ and $\mathrm{Fe}$ oxide. ${ }^{3,24,26}$

When one compares the $\mathrm{X}(\mathrm{Cr})$ at $0.6 \mathrm{~V}$ for $3.6 \mathrm{ks}$ with that at $0.6 \mathrm{~V}$ for $300 \mathrm{~s}$, the $\mathrm{Cr}$ oxide enriched at the outer portion in the initial $300 \mathrm{~s}$ spreads to the inner portion over time. When one compares the $\mathrm{X}(\mathrm{Cr})$ at $0.6 \mathrm{~V}$ for $3.6 \mathrm{ks}$ with that at $0.1 \mathrm{~V}$, the $\mathrm{Cr}$ enrichment is found to penetrate more readily into the inner part at $0.6 \mathrm{~V}$ than that at $0.1 \mathrm{~V}$. It is assumed that $\mathrm{Cr}$ enrichment progresses in the whole oxide film under longer oxidation and higher potential.

The dependence of the XPS signals on the detection angle indicates that the $\mathrm{Cr}$ and $\mathrm{OH}$ - ions preferentially distribute into the outer portion of the passive oxide. From similar results, some authors assumed a two-layer structure in which the outer layer consists of $\mathrm{Cr}$ hydroxide and the inner layer consists of $\mathrm{Cr}$ and Fe oxides. ${ }^{1,3,24-26}$ We question whether the thin oxide film at a 1-1.3 nm thickness (Fig. 1) can be divided into two layers.

Aging of the passive oxide during constant potential oxidation.The CD decays with time at a constant potential in the passive region. Figure 7 shows the $C D$ decay as a function of time on a logarithmic scale to $43.2 \mathrm{ks}(12 \mathrm{~h})$ during a potentiostatic oxidation at $0.6 \mathrm{~V}$ vs. SSC. The CD decreased with time from $1 \mathrm{~mA} \mathrm{~cm}^{-2}$ at $0.1 \mathrm{~s}$ to 0.02 $\mu \mathrm{A} \mathrm{cm}^{-2}$ at $43.2 \mathrm{ks}$ with a ratio of $\mathrm{d}[\log (i)] / \mathrm{d}[\log (t)]=-0.87$. If one assumes that the $\mathrm{CD}$ is consumed without dissolution of the metallic cations in the formation of the passive oxide, which acts as a barrier against ionic migration under a high electric field, the ratio should become $\mathrm{d}[\log (i)] / \mathrm{d}[\log (t)]=-1 .^{30}$ The smaller decay ratio in Fig. 7 indicates that the $\mathrm{CD}$ is partially consumed in the dissolution of the cations at the oxide/solution interface. ${ }^{30}$

The composition of the passive oxide was investigated during potentiostatic oxidation at $0.6 \mathrm{~V}$ using ex-situ XPS during the oxidation from $10 \mathrm{~s}$ to $43.2 \mathrm{ks}$ by a similar manner as shown in Figs. 2-4. In

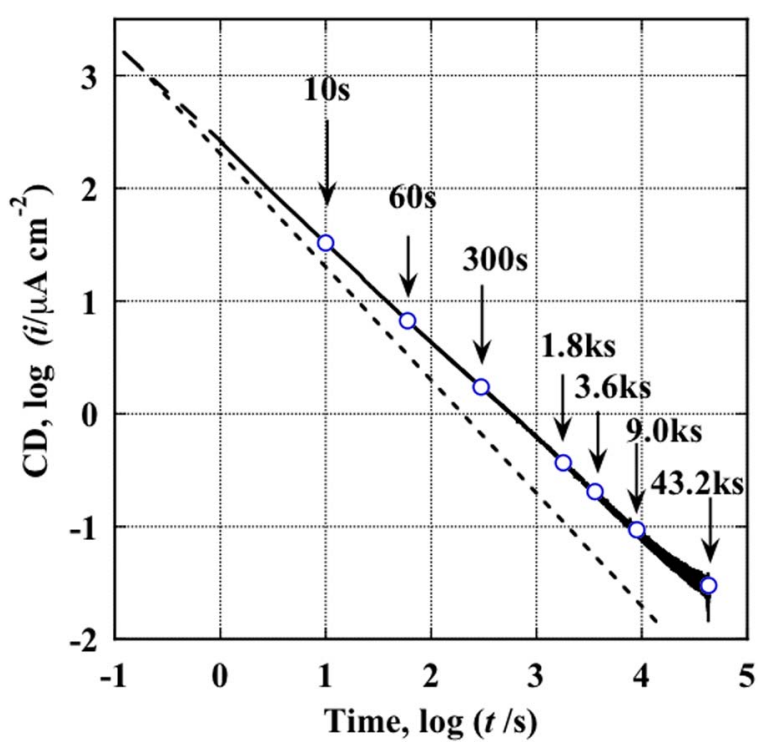

Figure 7. Decay of the current density under constant potential control at $0.6 \mathrm{~V}$ vs. $\mathrm{SSC}$ in a $0.1 \mathrm{M} \mathrm{H}_{2} \mathrm{SO}_{4}$ solution. The dashed line indicates the $\mathrm{d}(\mathrm{log}$ i) $/ \mathrm{d}(\log t)=-1$ relationship.

Fig. 8A, the cationic ratios of $\mathrm{Fe}, \mathrm{Cr}$, and $\mathrm{Ni}$ in the passive oxide are plotted as a function of the time period at constant oxidation of $0.6 \mathrm{~V}$, and in Fig. $8 \mathrm{~B}$, the ratio of $\mathrm{O}^{2-}$ to total oxygen $\left(\mathrm{O}^{2-}+\mathrm{OH}^{-}\right)$is plotted. The initial points in Figs. 8A and 8B indicate that the molar ratios in the air-formed oxide formed after polishing. In the air-formed oxide, $\mathrm{Cr}$ was already enriched. ${ }^{23,36}$ Because the polishing was conducted on a buff moistened by an aqueous solution containing fine alumina powder, $\mathrm{Fe}$ and $\mathrm{Ni}$ was most likely preferentially dissolved during the polishing step, resulting in $\mathrm{Cr}$ enrichment to a molar ratio of 0.43 in the air-formed oxide film. ${ }^{36}$ After reduction of the SS covered by the air-formed oxide at $-0.4 \mathrm{~V}, \mathrm{Cr}$ enrichment again occurs during potentiostatic oxidation at $0.6 \mathrm{~V}$ to a ratio of 0.57 in $10 \mathrm{ks}$. Kirchheim et al. also reported the gradual enrichment of $\mathrm{Cr}$ during the potentiostatic oxidation of $\mathrm{Fe}-18 \mathrm{Cr}$ alloys. ${ }^{23}$ The cationic ratio of $\mathrm{Fe}$, which had a molar ratio of 0.55 on the polished surface, decreased over time to approximately 0.4 . The Ni ratio in the passive oxide was maintained at approximately 0.05 . As shown in Fig. $8 \mathrm{~B}$, the $\mathrm{O}^{2-}$ ratio in the oxide increased from an initial value of 0.46 to 0.6 in $1 \mathrm{ks}$ and then remained constant. Maurice et al. reported a similar gradual increase of $\mathrm{O}^{2-}$ in the $\mathrm{Fe}-22 \mathrm{Cr}$ alloy oxide with oxidation time. ${ }^{24}$

The change in the oxide thickness during potentiostatic oxidation at $0.6 \mathrm{~V}$ was measured by in-situ ellipsometry. Figure 9 shows the change in the ellipsometric parameters (i.e., $\Psi$ and $\Delta$ ) during the initial $600 \mathrm{~s}$ (10 min) oxidation (Fig. 9A) and the subsequent oxidation from $10 \mathrm{~min}$ to $13 \mathrm{~h}$ (Fig. 9B). The parameters were scattered in a range of $(\Psi \pm 0.015) \mathrm{deg}$. and $(\Delta \pm 0.05) \mathrm{deg}$. The $\Delta$ value initially changes from $144.04 \mathrm{deg}$. for the reduced surface to $142.46 \mathrm{deg}$. at $10 \mathrm{~s}$ and then remained nearly constant at $142.45 \mathrm{deg}$. until $50 \mathrm{ks}$. The $\Psi$ value initially decreased from $33.725 \mathrm{deg}$. to $33.675 \mathrm{deg}$. in $10 \mathrm{~s}$ and then decreased to $33.64 \mathrm{deg}$. in $3.6 \mathrm{ks}$. The subsequent change is small and the $\Psi$ value became $33.66 \mathrm{deg}$. in $50 \mathrm{ks}$. Simultaneously, the reflectance change was measured, but the reflectance results were not used for the calculation of the film thickness in this study. The reflectance changed to $\Delta R / \mathrm{R}_{0}=-0.0076$ during the initial $5 \mathrm{~s}$ and then gradually changed to -0.043 in $43.2 \mathrm{ks}(12 \mathrm{~h})$. However, the $\Psi$ and $\Delta$ values remained nearly constant except during the initial oxidation. We believe that the gradual decrease in the reflectance is caused by a small change in the roughness of the surface. We assume that the reflectance is sensitive to roughness, but $\Psi$ and $\Delta$ are little influenced by the roughness and instead respond directly to the thickness change of the passive oxide. 
(A)
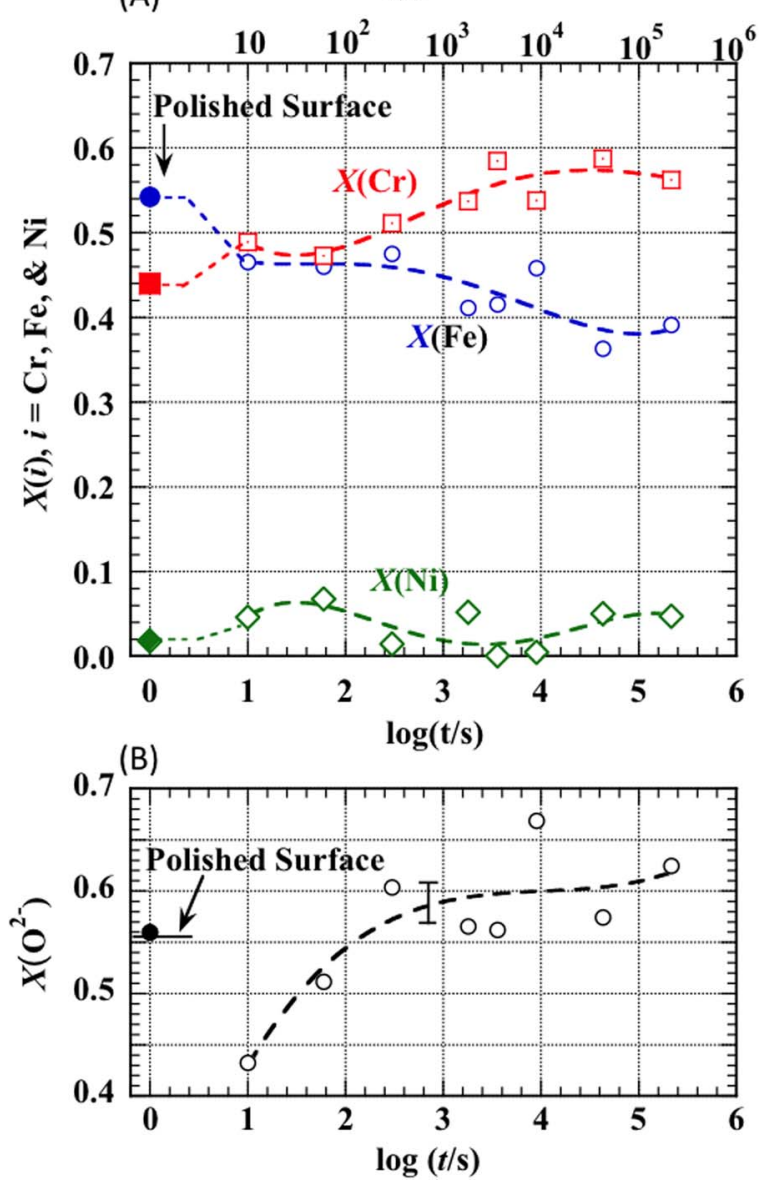

Figure 8. (A) Molar ratios of the $\mathrm{Fe}, \mathrm{Cr}$, and $\mathrm{Ni}$ cations and (B) molar ratio of $\mathrm{O}^{2-}$ to $\left(\mathrm{O}^{2-}+\mathrm{OH}^{-}\right)$in the passive oxide formed at $0.6 \mathrm{~V}$ in $0.1 \mathrm{M} \mathrm{H}_{2} \mathrm{SO}_{4}$ solution for various polarization times from $10 \mathrm{~s}$ to $43.2 \mathrm{ks}$. The solid marks on the left side indicate the molar ratios in the air-formed oxide on the mirror-like surface polished prior to passivation.

The film thickness was estimated from the change in $\Psi$ and $\Delta$ without using the reflectance change, which is influenced by both the surface roughness and oxide growth. For this estimate, we first calculated the complex refractive index $N_{\mathrm{s}}$ of the bare surface of the 304 SS from the values of the reduced surface: $\Psi_{0}=33.725 \mathrm{deg}$. and $\Delta_{0}=144.04 \mathrm{deg}$. The complex refractive index calculated was $N_{3}=$ $3.1282-\mathrm{j} 4.2143$ with the incidence angle at $\phi_{1}=60.0 \mathrm{deg}$. and the refractive index of a $0.1 \mathrm{M} \mathrm{H}_{2} \mathrm{SO}_{4}$ solution at $n_{1}=1.340$. By using the above constants $\left(n_{1}, N_{3}\right.$, and $\left.\phi_{1}\right)$, we calculated the thickness of the oxide film from $\Psi$ and $\Delta$ during the oxidation. The results are shown in Fig. 10. For the calculation we assumed a constant refractive index (from the real part of the complex refractive index, $N_{2}=n_{2}-\mathrm{j} k_{2}$ ) for the passive oxide (i.e., $n_{2}=2.0$ ) ${ }^{20}$ and from the change in $\Psi$ and $\Delta$, we estimated the extinction index (from the imaginary part of $N_{2}=$ $\left.n_{2}-\mathrm{j} k_{2}\right)$ and thickness $(d)$. From the scattering of the measurement parameters at $(\Psi \pm 0.015)$ deg. and $(\Delta \pm 0.05)$ deg., it is expected that the thickness can be calculated in a range of $\pm 0.05 \mathrm{~nm}$. Figure 10 shows the estimated thickness $(d)$ and extinction index $\left(k_{2}\right)$ for the passive oxide during the initial oxidation for $600 \mathrm{~s}$ and the subsequent oxidation to $50 \mathrm{ks}(13.9 \mathrm{~h})$. The thickness of the passive oxide grows to $1.38 \mathrm{~nm}$ in the initial $300 \mathrm{~s}$, decreases to $1.29 \mathrm{~nm}$, and finally becomes constant at approximately $1.3 \mathrm{~nm}$. Although $\mathrm{Cr}$ enrichment in the passive oxide occurs gradually during the long-term oxidation at $0.6 \mathrm{~V}$, the thickness does not increase except during the initial $10 \mathrm{~s}$ and remains nearly constant at $1.3 \mathrm{~nm}$.
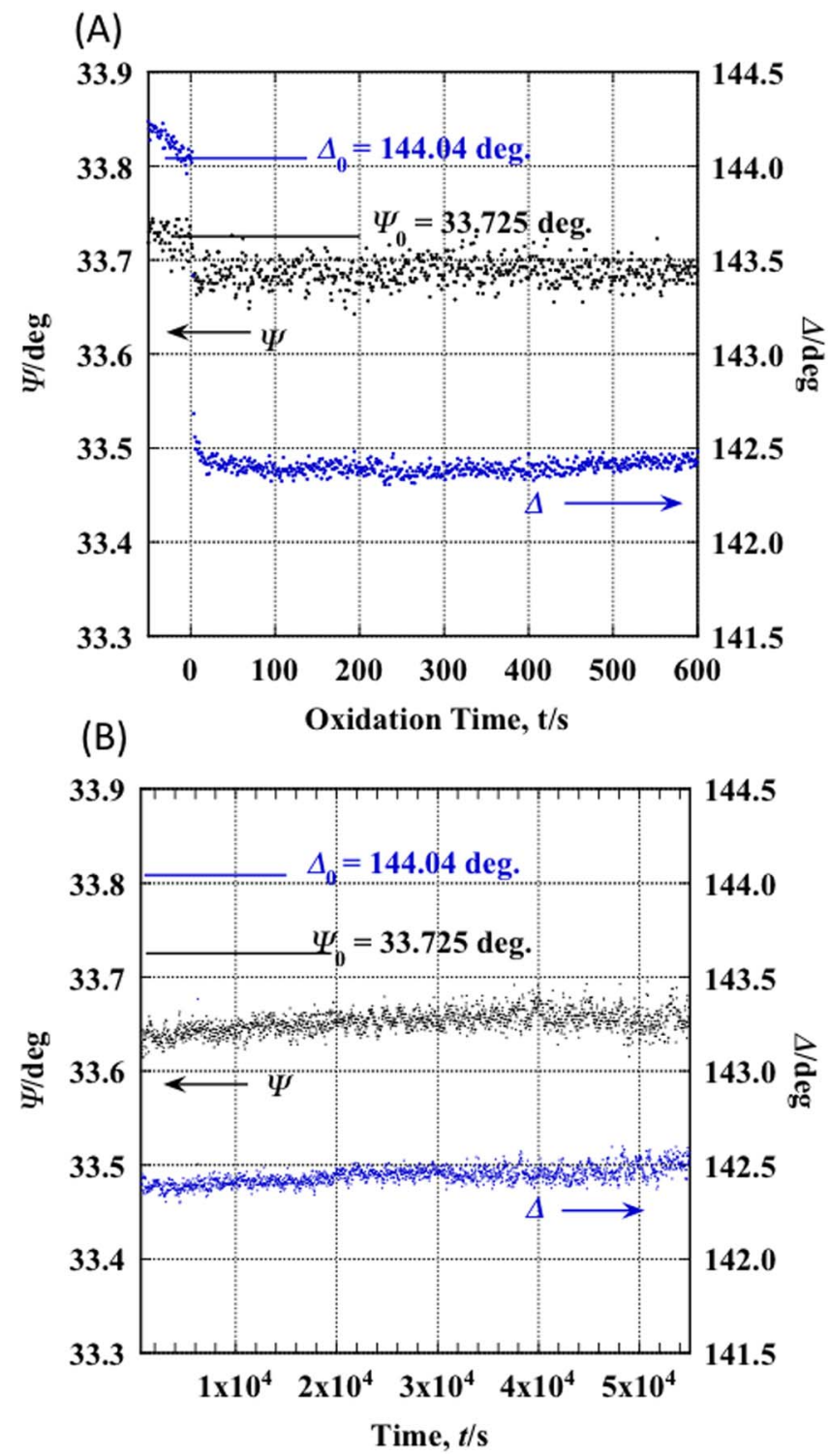

Figure 9. Change in $\Psi$ and $\Delta$ from the initial values at $\Psi_{0}=33.725 \mathrm{deg}$. and $\Delta_{0}=144.04$ deg. during the oxidation time at a constant potential of $0.6 \mathrm{~V}$, (A) the initial period to $600 \mathrm{~s}(10 \mathrm{~min})$, and (B) the period from $600 \mathrm{~s}$ to $55 \mathrm{ks}$ (15.3 h).

The film thickness on the passive oxide has been estimated by XPS from the ratio of the signal intensity of the metallic elements in the substrate to the intensity of the ionic elements in the oxide, with the assumption of a mean free path or penetration distance of the photoelectrons. ${ }^{3,21,24,34}$ Figure 11 shows the intensity ratios of the metallic to the ionic components of $\mathrm{Fe}$ and $\mathrm{Cr}$ as a function of the passivation time at $0.6 \mathrm{~V}$. In Fig. 11, the decrease of the relative intensity of the metallic $\mathrm{Fe}$ and $\mathrm{Cr}$ over time is observed. In the oxide, if the mean free paths of individual photoelectrons from the metallic elements of $\mathrm{Fe}$ and $\mathrm{Cr}$ in the substrate were constant, the decrease of the relative intensity of the metallic elements would indicate a gradual increase of the thickness of the oxide film with time. However, this outcome disagrees with the ellipsometric results shown in Figs. 9 and 10. Because the oxide film is assumed to be denser with time since the $\mathrm{O}^{2-}$ component increases relative to $\mathrm{OH}^{-}$(Fig. $8 \mathrm{~B}$ ) and more $\mathrm{Cr}-$ enriched oxide is produced (Fig. 8A), the mean free path in the oxide is not constant, but it may be expected to be shorter. We believe that the small growth in thickness of the oxide film with time on the basis 

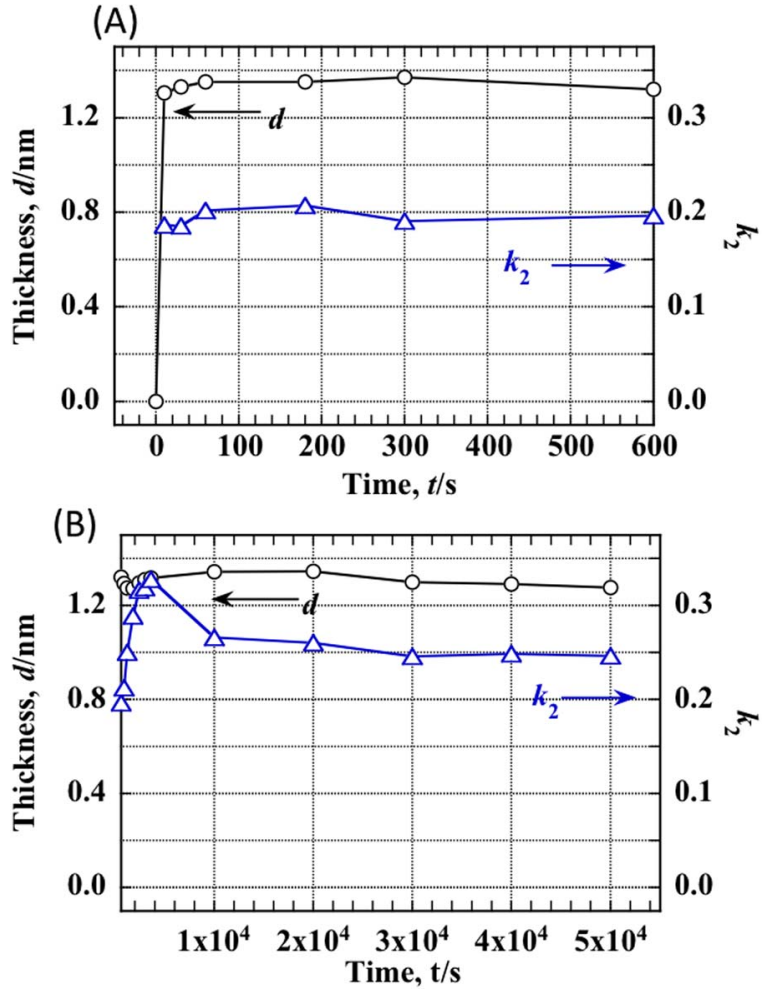

Figure 10. Film thickness of the passive oxide $(d)$ as a function of oxidation time $(t)$ at a constant potential at $0.6 \mathrm{~V}$ (A) for the initial period to $600 \mathrm{~s}$ (10 $\mathrm{min})$, and (B) the period from $600 \mathrm{~s}$ to $50 \mathrm{ks}(13.9 \mathrm{~h})$.

of ellipsometry is not contradictory to the results in Fig. 11 from the XPS measurements.

The thickness was also estimated from a depth profile of each element by $\mathrm{Ar}^{+}$ion sputtering with an assumption of sputter efficiency. ${ }^{24,33}$ In this study we did not use sputtering for the depth profile because this technique may induce a change of the oxidized states of the elements and oxygen state $\left(\mathrm{O}^{2-}\right.$ or $\left.\mathrm{OH}^{-}\right)$.

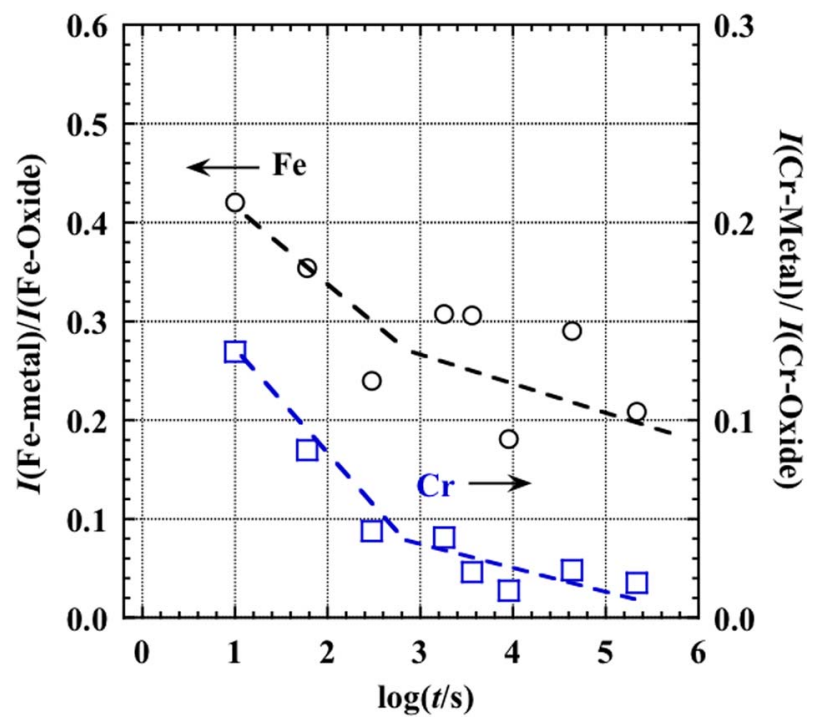

Figure 11. Intensity of the XPS peak of $\mathrm{Fe}(0)$ and $\mathrm{Cr}(0)$ relative to those of $\mathrm{Fe}$ (oxide) and $\mathrm{Cr}$ (oxide), respectively, as a function of time.

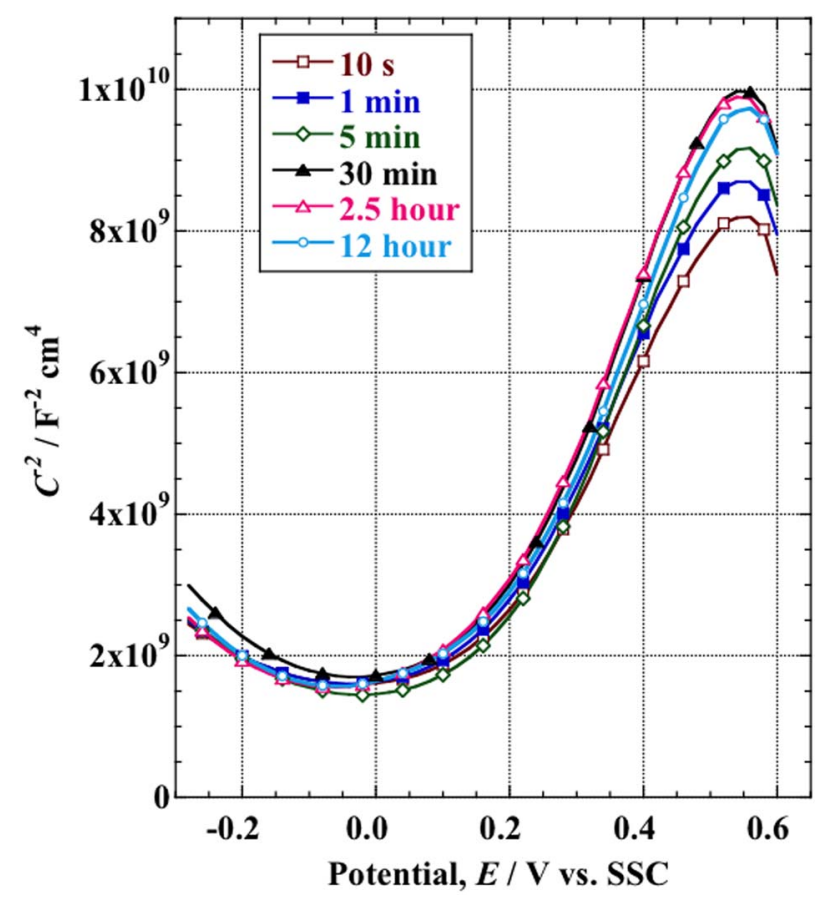

Figure 12. Mott-Schottky plot of the capacitance data on the passivated SUS304 SS at $0.6 \mathrm{~V}$ vs. SSC for $10 \mathrm{~s}, 60 \mathrm{~s}, 300 \mathrm{~s}, 9 \mathrm{ks}$, and $43.2 \mathrm{ks}$ in a $0.1 \mathrm{M} \mathrm{H}_{2} \mathrm{SO}_{4}$ solution.

Semiconducting properties during aging under potentiostatic oxidation.- $\mathrm{Cr}$ was gradually enriched in the passive oxide during oxidation under constant potential control at $0.6 \mathrm{~V}$. However, the thickness of the passive oxide remains nearly constant at $1.3 \mathrm{~nm}$. The enrichment of $\mathrm{Cr}$ can be expected to influence the semiconducting properties of the passive oxide. To estimate the semiconducting properties, the Mott-Schottky relationship (Eq. 6) , $^{5,10,20}$ was measured for the passive oxide formed at $0.6 \mathrm{~V}$ for $10 \mathrm{~s}$ to $4.32 \mathrm{ks}$.

$$
C_{\mathrm{sp}}{ }^{-2}=\left(2 / \varepsilon \varepsilon_{0} N_{\mathrm{D}} \mathrm{e}\right)\left(E-E_{\mathrm{FB}}-\mathrm{k} T / \mathrm{e}\right)
$$

where $C_{\mathrm{sp}}$ is the space charge capacitance, $N_{\mathrm{D}}$ is the donor density, $\varepsilon$ is the dielectric constant, $\varepsilon_{0}$ is the vacuum permittivity, and $E_{\mathrm{FB}}$ is the flatband potential. The measured capacitance $(C)$ consists of the space charge capacitance in the passive oxide and the electric double layer capacitance at the oxide/solution interface. In general, because the reciprocal of the electric double layer capacitance is assumed to be much smaller than the reciprocal of the space charge capacitance, the contribution from the electric double layer capacitance to the measured capacitance is much smaller than that from the space charge capacitance. Therefore, the measured capacitance is assumed to be approximately equal to the space charge capacitance. The $C^{-2}$ vs. $E$ relationship for the oxide films formed at $0.6 \mathrm{~V}$ for various time periods is shown in Fig. 12. Here, the impedance was measured at a frequency of $f=13 \mathrm{~Hz}$ with a step-wise potential decrease from $0.60 \mathrm{~V}$ at a step height of $0.02 \mathrm{~V}$ and a step width of $10 \mathrm{~s}$. The capacitance was calculated from the imaginary part $(Y)$ of the complex impedance $(Z=X+\mathrm{j} Y)$.

$$
C=1 /(-2 \pi f Y)
$$

$C^{-2}$ initially increased with a decrease in potential from $0.60 \mathrm{~V}$ and exhibited a maximum at approximately $0.5 \mathrm{~V}$. At potentials between $0.5 \mathrm{~V}$ and $0.2 \mathrm{~V}$, a linear relationship was observed, and the positive slope indicates that the passive oxide is an n-type semiconductor. The donor density was calculated from the slope of $\left(\mathrm{d} C^{-2} / \mathrm{d} E\right)$ in the linear region assuming that $\varepsilon=15.6 .{ }^{20}$ The calculated donor density is shown in Fig. 13. During the aging process, the donor density decreased from $4.5 \times 10^{20} \mathrm{~cm}^{-3}$ to $3.5 \times 10^{20} \mathrm{~cm}^{-3}$ as the oxidation time increased 


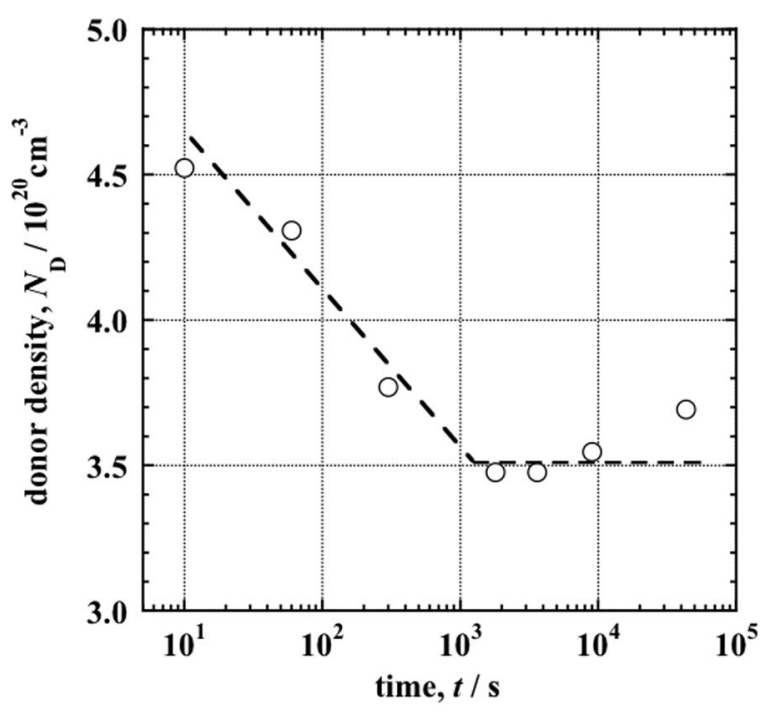

Figure 13. Donor density of the passive oxide film formed on SUS304 SS at $0.6 \mathrm{~V}$ vs. $\mathrm{SSC}$ for various times in a $0.1 \mathrm{M} \mathrm{S}_{2} \mathrm{SO}_{4}$ solution. The dielectric constant of the passive oxide was assumed to be 15.6.

from $10 \mathrm{~s}$ to $1.8 \mathrm{ks}$ and then remained at $3.5 \times 10^{20} \mathrm{~cm}^{-3}$ or slightly increased for time periods longer than $1.8 \mathrm{ks}$.

The change in the semiconducting property of the passive oxide as a function of oxidation time was further examined by measuring the redox current of $\mathrm{Fe}^{3+} / \mathrm{Fe}^{2+}$ in a $0.1 \mathrm{M} \mathrm{H}_{2} \mathrm{SO}_{4}$ solution on the passive oxide. ${ }^{37}$ Because electron transfer on the passivated SS is substantially influenced by the semiconducting property of the passive oxide, the redox current between $\mathrm{Fe}^{3+}$ and $\mathrm{Fe}^{2+}$ in a $0.1 \mathrm{M} \mathrm{H}_{2} \mathrm{SO}_{4}$ solution on the passivated SS was measured as a function of the oxidation time at $0.6 \mathrm{~V}$.

$$
\mathrm{Fe}^{3+}+\mathrm{e}^{-} \rightleftarrows \mathrm{Fe}^{2+}
$$

Figure 14 shows the $\mathrm{Fe}^{3+} / \mathrm{Fe}^{2+}$ redox current on a logarithmic scale measured as a function of the potential after passivation of the SS at $0.6 \mathrm{~V}$ for $3.6 \mathrm{ks}$. For comparison, the redox current on a Pt electrode is also plotted in Fig. 14. The CD was inhibited significantly on the

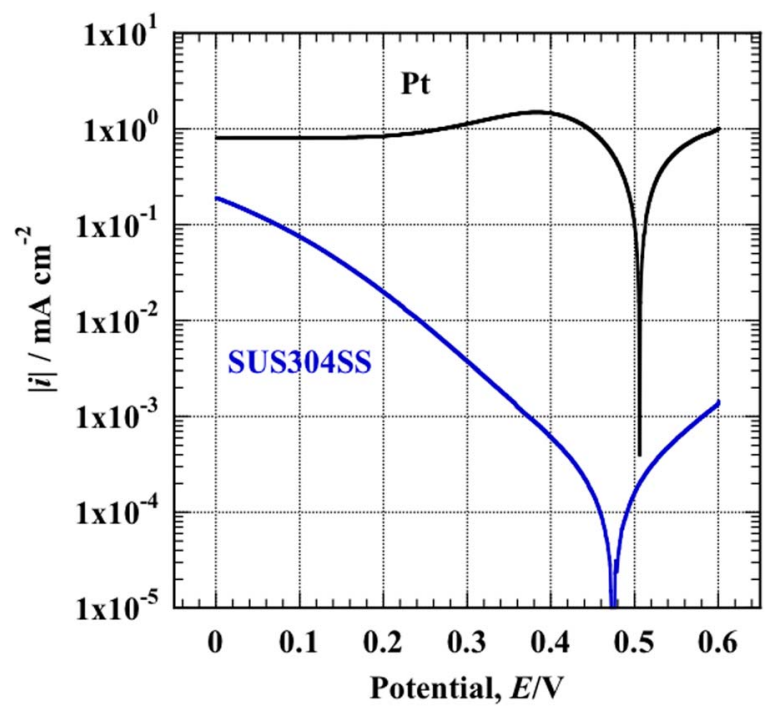

Figure 14. $\mathrm{CD}$ on a logarithmic scale as a function of the potential for the $\mathrm{Fe}^{3+} / \mathrm{Fe}^{2+}$ redox reaction on SUS304 SS passivated at $0.6 \mathrm{~V}$ for $1 \mathrm{~h}$ in a $0.1 \mathrm{M} \mathrm{H}_{2} \mathrm{SO}_{4}$ solution. For comparison, the $\mathrm{CD}$ as a function of the potential on the Pt electrode was plotted. The sweep rate of the potential was $2 \mathrm{mV} \mathrm{s}^{-1}$.
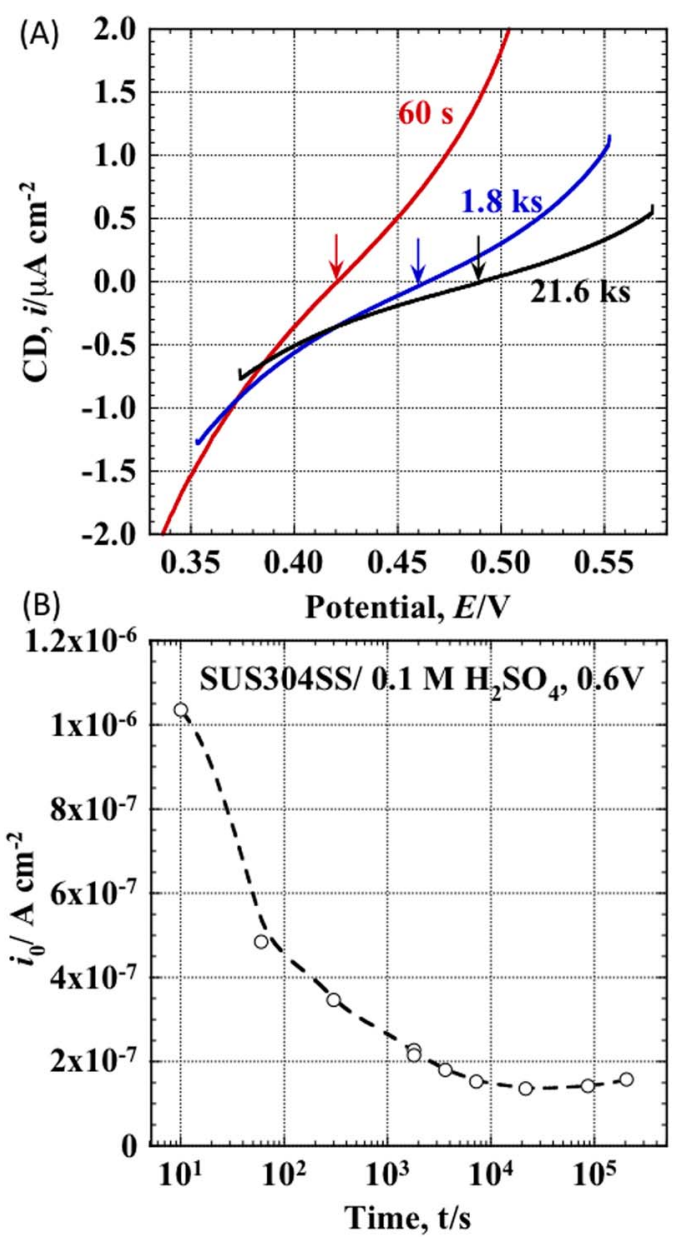

Figure 15. (A) $\mathrm{CD}$ as a function of the potential for the $\mathrm{Fe}^{3+} / \mathrm{Fe}^{2+}$ redox reaction on $304 \mathrm{SS}$ passivated at $0.6 \mathrm{~V}$ for $60 \mathrm{~s}, 1.8 \mathrm{ks}$, and $21.6 \mathrm{ks}$ in a $0.1 \mathrm{M}$ $\mathrm{H}_{2} \mathrm{SO}_{4}$ solution. (B) Exchange $\mathrm{CD}$ for the $\mathrm{Fe}^{3+} / \mathrm{Fe}^{2+}$ redox reaction on 304 SS passivated at $0.6 \mathrm{~V}$ for various times.

passivated SS, and the zero-current potential $\left(E_{(\mathrm{i}=0)}\right)$ shifted to a more negative potential compared to that on the Pt electrode. Similar CD vs. potential curves were measured for various oxidation times. Examples of the CD-potential curves near the zero-current potential $\left(E_{(\mathrm{i}=0}\right)$ are shown in Fig. 13A. With longer oxidation times, the slope of $(\mathrm{d} i / \mathrm{d} E)$ near $E_{(\mathrm{i}=0)}$ becomes smaller. From the reciprocal of the polarization resistance, $R_{\mathrm{p}}{ }^{-1}=(\mathrm{d} i / \mathrm{d} E)$, we estimated the exchange $\mathrm{CD}\left(i_{0}\right)$ of the redox reaction.

$$
i_{0}=2.303^{-1} R_{\mathrm{p}}^{-1}\left[\left(1 / \beta_{\mathrm{A}}\right)+\left(1 / \beta_{\mathrm{C}}\right)\right]^{-1}
$$

where $\beta_{\mathrm{A}}$ and $\beta_{\mathrm{C}}$ are the Tafel slopes of the anodic and cathodic currents, respectively, which were determined from the log $|i|$ vs. potential relationship shown in Fig. 14 for the SS passivated at $0.6 \mathrm{~V}$ for $3.6 \mathrm{ks}$. The exchange $\mathrm{CD}$ of the redox reaction thus calculated is plotted in Fig. 15B as a function of the oxidation time on a logarithmic scale. For $10 \mathrm{~s}$ of oxidation, the exchange $\mathrm{CD}$ is approximately $1.02 \mu \mathrm{A} \mathrm{cm}^{-2}$ and decreased to $0.15 \mu \mathrm{A} \mathrm{cm}^{-2}$ as the time increased to $10 \mathrm{ks}$. The results indicate that aging the passive oxide reduces the rate of the redox reaction to $1 / 8$ compared to that in the initial $10 \mathrm{~s}$ of oxidation. During the aging process for long oxidation times, because $\mathrm{Cr}$ is enriched more in the oxide film without thickness growth, it is thus inferred that the Cr-enriched oxide film more effectively inhibits electron transfer from the SS substrate to the redox species in the electrolyte. 


\section{Discussion}

Composition of the passive oxide.-Based on the XPS results on the passivated 304 SS shown in Fig. 4A, the passive film consists of $50-60 \% \mathrm{Cr}$ oxide and $40-50 \% \mathrm{Fe}$ oxide with a small amount of $\mathrm{Ni}$ oxide. The Cr oxide content in the passive oxide increased at higher potentials in the passive region but decreased in the transpassive region. The decrease in the transpassive region was caused by dissolution of $\mathrm{CrO}_{4}{ }^{2-}$ ions. With the change in the $\mathrm{Cr}$ ratio, the ratio of $\mathrm{O}^{2-}$ to total oxygen increased at higher potentials in the passive region and decreased in the transpassive region, as shown in Fig. 4B. The Fe oxide component remained constant at approximately $44 \%$ in the passive region from $0.1 \mathrm{~V}$ to $0.9 \mathrm{~V}$ and increased at higher potentials in the transpassive region. The Ni content in the passive oxide is consistent with a molar ratio of approximately 0.07 at an initial passive potential of $0.1 \mathrm{~V}$ and becomes lower at higher potentials.

As shown in Fig. 8A, Cr enrichment was observed prior to anodic oxidation. The air-formed oxide film on the surface polished by an aqueous abrasive solution containing suspended alumina powder exhibited a molar ratio of $\mathrm{Cr}$ of approximately $0.44 .{ }^{23,36}$ Following the removal of the air-formed oxide film by reduction at $-0.4 \mathrm{~V}$, the potentiostatic oxidation at $0.6 \mathrm{~V}$ again induced $\mathrm{Cr}$ enrichment to a molar ratio of 0.57 and depletion of $\mathrm{Fe}$ in the passive oxide. During aging at a constant potential of $0.6 \mathrm{~V}$, enrichment of $\mathrm{Cr}$ and $\mathrm{O}^{2-}$ in the passive oxide gradually occurs. However, the oxide thickness remains $1.3 \mathrm{~nm}$ during oxidation from $10 \mathrm{~s}$ to $40 \mathrm{ks}$ (Fig. 10). Although the thickness remains constant, the $\mathrm{CD}$ decays from $30 \mu \mathrm{A} \mathrm{cm}^{-2}$ at $10 \mathrm{~s}$ to $0.025 \mu \mathrm{A} \mathrm{cm}^{-2}$ at $43.2 \mathrm{ks}$ (Fig. 6). The decay of CD was not caused by a thickening of the oxide but by enrichment of $\mathrm{Cr}_{\mathrm{r}}$ and $\mathrm{O}^{2-}$.

The dependence of the XPS signals on the detection angle, as shown in Figs. 5 and 6, indicates that the $\mathrm{Cr}$ and $\mathrm{OH}^{-}$ions preferentially distribute to the outer portion of the passive oxide rather than the inner portion.

The composition of a typical passive oxide (e.g., the passive oxide at $0.6 \mathrm{~V}$ ) can be described as follows. Under a quasi-stationary state after $10 \mathrm{ks}$ of oxidation, the average ratios of the metal ions are 0.57 $\mathrm{Cr}, 0.40 \mathrm{Fe}$, and $0.03 \mathrm{Ni}$, and the molar ratios of the oxygen ion $\left(\mathrm{O}^{2-}\right)$ and hydroxide ion $\left(\mathrm{OH}^{-}\right)$are 0.6 and 0.4 , respectively. $\mathrm{Cr}$ and $\mathrm{OH}^{-}$ are distributed to the outer layer of the passive oxide at higher ratios than the average; in contrast, $\mathrm{Fe}$ and $\mathrm{O}^{2-}$ are distributed to the inner layer at higher ratios.

Enrichment of Crin the passive oxide.-For the enrichment of $\mathrm{Cr}$ in the passive oxide, a relatively simple mechanism using a stationary state approximation can be considered. We assume two sets of ionic transfer reactions at the two respective interfaces.

The first process involves a mechanism that includes the preferential oxidation of $\mathrm{Cr}$ metal to $\mathrm{Cr}$ ion at the steel/oxide interface via the following interfacial reactions.

$$
\begin{gathered}
\mathrm{Fe}(\mathrm{M}) \rightarrow \mathrm{Fe}^{2+\text { or } 3+}(\mathrm{O})+(2 \text { or } 3) \mathrm{e}^{-}(\mathrm{M}) \\
\mathrm{Cr}(\mathrm{M}) \rightarrow \mathrm{Cr}^{3+}(\mathrm{O})+3 \mathrm{e}^{-}(\mathrm{M}) \\
\mathrm{Ni}(\mathrm{M}) \rightarrow \mathrm{Ni}^{2+}(\mathrm{O})+2 \mathrm{e}^{-}(\mathrm{M})
\end{gathered}
$$

where $(\mathrm{M})$ and $(\mathrm{O})$ indicate the metal and oxide phase, respectively. Because $\mathrm{Cr}$ exhibits a lower equilibrium oxygen pressure at the metal/oxide interface than that of $\mathrm{Fe}$ and $\mathrm{Ni}$, according to the wellknown Ellingham diagram, $\mathrm{Cr}$ is likely to be preferentially oxidized at the interface.

The second process is the preferential dissolution of $\mathrm{Fe}$ and $\mathrm{Ni}$ ions at the oxide/solution interface via the following interfacial reactions.

$$
\begin{aligned}
& \mathrm{Fe}^{3+}(\mathrm{O}) \rightarrow \mathrm{Fe}^{3+}(\mathrm{S}) \\
& \mathrm{Cr}^{3+}(\mathrm{O}) \rightarrow \mathrm{Cr}^{3+}(\mathrm{S}) \\
& \mathrm{Ni}^{2+}(\mathrm{O}) \rightarrow \mathrm{Ni}^{2+}(\mathrm{S})
\end{aligned}
$$

where $(\mathrm{S})$ indicates the solution phase. The relation between the $\mathrm{Cr}$ enrichment and the preferential dissolution of $\mathrm{Fe}$ in $\mathrm{Fe}-\mathrm{Cr}$ alloys was previously discussed by Kirchheim et al..$^{23}$ and Legrand et al. ${ }^{25}$

Regarding the origin of the $\mathrm{Cr}$ enrichment, we can further consider the different migration rates of the metal ions in the passive oxide. ${ }^{23}$ When the migration rate of the $\mathrm{Cr}$ ion is relatively slower than that of the other metal ions, $\mathrm{Cr}$ should be enriched in the passive oxide, especially in the inner layer of the oxide. However, the simulation will become somewhat complicated when different migration rates are considered; thus, we disregard the contribution of migration rates. Next, we semi-quantitatively discuss the enrichment of $\mathrm{Cr}$ from the preferential oxidation at the steel/oxide interface and the preferential dissolution at the oxide/solution interface using a stationary state approximation.

We assume that the oxidation rates $\left(r_{\mathrm{i}(\mathrm{M} / \mathrm{O})}\right)$ of $\mathrm{Fe}, \mathrm{Cr}$, and $\mathrm{Ni}$ at the metal/oxide interface are described by a product of the molar ratio $\left(X_{\mathrm{i}(\mathrm{M})}\right)$ of the steel substrate at the interface and the rate constant, which is independent of the composition of the substrate steel at the interface:

$$
r_{\mathrm{i}(\mathrm{M} / \mathrm{O})}=k_{\mathrm{i}(\mathrm{M} / \mathrm{O})} X_{\mathrm{i}(\mathrm{M})}
$$

where $\mathrm{i}=\mathrm{Fe}, \mathrm{Cr}$, or $\mathrm{Ni}$ and $k_{\mathrm{i}(\mathrm{M} / \mathrm{O})}$ is the rate constant for the $\mathrm{i}$ species in Reactions 10 to 12 . In a similar fashion, we assume that the dissolution rates $\left(r_{\mathrm{i}(\mathrm{O} / \mathrm{S})}\right)$ of $\mathrm{Fe}, \mathrm{Cr}$, and $\mathrm{Ni}$ at the oxide/solution interface are described by a product of the molar ratios $\left(X_{\mathrm{i}(\mathrm{O})}\right)$ of the oxide phase at the interface and the rate constant $\left(k_{\mathrm{i}(\mathrm{O} / \mathrm{S})}\right)$, which is independent of the composition of the oxide:

$$
r_{\mathrm{i}(\mathrm{O} / \mathrm{S})}=k_{\mathrm{i}(\mathrm{O} / \mathrm{S})} X_{\mathrm{i}(\mathrm{O})}
$$

The mutual relationship between $r_{\mathrm{i}(\mathrm{M} / \mathrm{O})}$ and $r_{\mathrm{i}(\mathrm{O} / \mathrm{S})}(\mathrm{i}=\mathrm{Fe}, \mathrm{Cr}$, and $\mathrm{Ni})$ should provide the composition of the passive oxide. The change in the average molar ratio of the three metal cations (i.e., $\mathrm{Fe}, \mathrm{Cr}$, and $\mathrm{Ni}$ ) in the oxide film can be described as follows:

$$
\left(\mathrm{d} X_{\mathrm{i}(\mathrm{O})} / \mathrm{dt}\right) d=r_{\mathrm{i}(\mathrm{M} / \mathrm{O})}-r_{\mathrm{i}(\mathrm{O} / \mathrm{S})}
$$

where $d$ is thickness of the oxide film. When one adopts the stationary state as a first approximation, the molar ratios in the oxide film are assumed to be constant and independent of time.

$$
\mathrm{d} X_{\mathrm{i}(\mathrm{O})} / \mathrm{dt}=0
$$

From Eqs. 16-19, the molar ratio in the oxide film can be related to the ratio in the metal phase.

$$
X_{\mathrm{i}(\mathrm{O})}=\left(k_{\mathrm{i}(\mathrm{M} / \mathrm{O})} / k_{\mathrm{i}(\mathrm{O} / \mathrm{S})}\right) X_{\mathrm{i}(\mathrm{M})}
$$

From the experimental results for $\mathrm{Cr}$ enrichment $\left(X_{\mathrm{Cr}(\mathrm{O})}>X_{\mathrm{Cr}(\mathrm{M})}\right)$ in the oxide film, the rate constant should be consistent with the following condition.

$$
k_{\mathrm{Cr}(\mathrm{M} / \mathrm{O})}>k_{\mathrm{Cr}(\mathrm{O} / \mathrm{S})}
$$

For Fe depletion, the rate constant should exhibit an inverse condition, that is,

$$
\left(k_{\mathrm{Fe}(\mathrm{M} / \mathrm{O})}<k_{\mathrm{Fe}(\mathrm{O} / \mathrm{S})}\right)
$$

For a more quantitative treatment, we conjecture that either of the two sets of ionic transfer reactions preferentially trigger $\mathrm{Cr}$ enrichment in the passive oxide. When the ionic transfer reaction at the metal/oxide interface controls the enrichment and no preferential dissolution occurs at the oxide/solution interface, the molar ratio in the dissolution reaction is directly proportional to the molar ratio of the oxide film, that is

$$
k_{\mathrm{Fe}(\mathrm{O} / \mathrm{S})}=k_{\mathrm{Cr}(\mathrm{O} / \mathrm{S})}=k_{\mathrm{Ni}(\mathrm{O} / \mathrm{S})}
$$

From Eq. 20,

$$
X_{\mathrm{Cr}(\mathrm{O})}=\left(k_{\mathrm{Cr}(\mathrm{M} / \mathrm{O})} / k_{\mathrm{Fe}(\mathrm{M} / \mathrm{O})}\right)\left(X_{\mathrm{Cr}(\mathrm{M})} / X_{\mathrm{Fe}(\mathrm{M})}\right) X_{\mathrm{Fe}(\mathrm{O})}
$$

Using the experimental results of $X_{\mathrm{Cr}(\mathrm{O})}=0.57$ and $X_{\mathrm{Fe}(\mathrm{O})}=0.40$ in Figs. 4 and $8 \mathrm{~A}$ and the substrate composition of $X_{\mathrm{Cr}(\mathrm{M})}=0.18$ and $X_{\mathrm{Fe}(\mathrm{M})}=0.71$, the ratio of the reaction rate constants is

$$
\left(k_{\mathrm{Cr}(\mathrm{M} / \mathrm{O})} / k_{\mathrm{Fe}(\mathrm{M} / \mathrm{O})}\right)=5.6
$$


Thus, the oxidation rate of $\mathrm{Cr}$ is 5.6 times larger than that of $\mathrm{Fe}$ at the metal/oxide interface.

When the ionic transfer reaction at the oxide/solution interface preferentially controls the $\mathrm{Cr}$ enrichment (i.e., when the preferential dissolution of $\mathrm{Fe}$ and $\mathrm{Ni}$ occurs), the oxidation reaction rate of each metallic element at the metal/oxide interface is directly proportional to the molar ratio of the steel substrate.

$$
k_{\mathrm{Fe}(\mathrm{M} / \mathrm{O})}=k_{\mathrm{Cr}(\mathrm{M} / \mathrm{O})}=k_{\mathrm{Ni}(\mathrm{M} / \mathrm{O})}
$$

From Eq. 20,

$$
X_{\mathrm{Cr}(\mathrm{O})}=\left(k_{\mathrm{Fe}(\mathrm{O} / \mathrm{S})} / k_{\mathrm{Cr}(\mathrm{O} / \mathrm{S})}\right)\left(X_{\mathrm{Cr}(\mathrm{M})} / X_{\mathrm{Fe}(\mathrm{M})}\right) X_{\mathrm{Fe}(\mathrm{O})}
$$

Using a similar substitution of experimental results,

$$
\left(k_{\mathrm{Cr}(\mathrm{O} / \mathrm{S})} / k_{\mathrm{Fe}(\mathrm{O} / \mathrm{S})}\right)=0.18
$$

Thus, the dissolution rate of $\mathrm{Cr}$ is 5.6 times smaller than that of $\mathrm{Fe}$ at the oxide/solution interface. We cannot easily determine which of the two sets of ionic transfer reactions control $\mathrm{Cr}$ enrichment. If the difference in the oxidation rate constant of the metallic elements at the metal/oxide interface induces a change in composition, the enrichment of $\mathrm{Cr}$ in the passive oxide will be observed near the metal/oxide interface. If the difference in the dissolution rate constant at the oxide/solution interface induces a change in composition, the enrichment of $\mathrm{Cr}$ will be observed near the oxide/solution interface. Based on the multiple-angle-of-detection results of XPS shown in Figs. 5 and 6, Cr enriched occurs predominantly in the outer oxide layer. Therefore, the preferential dissolution at the oxide/solution interface is most likely the origin of $\mathrm{Cr}$ enrichment in the passive oxide. When Kirchheim et al. $^{23}$ assumed that the ratio of the rate constant of Fe dissolution to that of $\mathrm{Cr}$ dissolution at the oxide/solution interface was 500, which was evaluated from the stationary passive $\mathrm{CDs}$ of pure $\mathrm{Fe}$ and $\mathrm{Cr}$ in a sulfuric acid solution, they indicated that the $\mathrm{Cr}$ enrichment was over-estimated. They then assumed a difference in rate constants for the $\mathrm{Fe}$ and $\mathrm{Cr}$ ions in the ionic migration in the oxide film. When a ratio of the migration rate constant of $\mathrm{Fe}$ ions to that of $\mathrm{Cr}$ ion was assumed to be 8 , the estimated $\mathrm{Cr}$ enrichment agreed with the experimental results. Because the rate constant of the ionic migration, for which they assumed to be a simple expression, can be replaced by the ratio of the dissolution rate constant, ${ }^{23}$ the value of 5.6 determined in this study may not be considered too different from the value of 8 evaluated by Kirchheim et al. Additionally, Legrand et al. suggested a model for the $\mathrm{Cr}$ enrichment in the passive oxide on $\mathrm{Fe}-\mathrm{Cr}$ alloys with the assumption of the selective dissolution of $\mathrm{Fe}^{25}$

Relationship between Cr enrichment and the semiconducting properties.-During passivation at constant potential, the $\mathrm{CD}$ decayed with time and $\mathrm{Cr}$ was simultaneously enriched in the oxide film. In addition, the donor density of the oxide film decreased. The film thickness remained nearly constant at $1.3 \mathrm{~nm}$ from $10 \mathrm{~s}$ to $50 \mathrm{ks}$, even though the $\mathrm{CD}$ decreased 3 orders of magnitude from $30 \mu \mathrm{A} \mathrm{cm}^{-2}$ at $10 \mathrm{~s}$ to $0.025 \mu \mathrm{A} \mathrm{cm}{ }^{-2}$ at $43.2 \mathrm{ks}$. If we assume that the CD is controlled by ionic migration caused by a high electric field, $(\mathrm{d} E / \mathrm{d} x)$, in the oxide film, the decay of $\mathrm{CD}$ is accompanied by a gradual growth of the oxide thickness. ${ }^{38,39}$

$$
i=i_{0} \exp [(z a \mathrm{e} / \mathrm{k} T)(\mathrm{d} E / \mathrm{d} x)]
$$

where $a$ is the half jump distance of the migrated species (or an activation distance), $z$ is the valence of the migrating species, and $i_{0}$ is the migration $\mathrm{CD}$ at zero field. The electric field of $\mathrm{d} E / \mathrm{d} x$ is replaced with an average electric filed $(\Delta E / d)$ in the oxide film with a thickness (d):

$$
i=i_{0} \exp [(z a \mathrm{e} / \mathrm{k} T)(\Delta E / d)]
$$

where $\Delta E$ is the potential drop in the oxide film. If the composition and properties of the oxide film do not change with the aging time, $i_{0}$ and $z a$ remain constant. Therefore, a logarithm of CD (i) decays proportionally with $(1 / d)$ under constant potential control.

The results indicate that the film thickness was nearly constant and did not change with the aging time in which $\mathrm{Cr}$ was enriched relative to $\mathrm{Fe}$ and $\mathrm{Ni}$. In addition, $\mathrm{O}^{2-}$ was enriched relative to $\mathrm{OH}^{-}$. The gradual decay of $\mathrm{CD}$ was not induced by an increase in the thickness but by a change in the composition and properties of the oxide film (i.e., the change in the migration $\mathrm{CD}$ at zero field, $i_{0}$ ). The value of $i_{0}$ is assumed to be proportional to the density of mobile lattice defects $\left(N_{\mathrm{L}}\right)$ and a negative exponential of the activation energy $\left(\Delta G^{\#}\right)$ for transfer between the stable lattice sites.

$$
i_{0} \approx N_{\mathrm{L}} \exp \left(-\Delta G^{\#} / \mathrm{kT}\right)
$$

Therefore, the enrichment of $\mathrm{Cr}$ and $\mathrm{O}^{2-}$ in the oxide film during aging induces a decrease in mobile lattice defects and an increase in the activation energy. With the enrichment of $\mathrm{Cr}$ and $\mathrm{O}^{2-}$, a more protective oxide film is formed that can sustain a potential drop in the oxide film caused by a smaller thickness.

The CD during the aging by constant potential oxidation at $0.6 \mathrm{~V}$ corresponds to a migration $\mathrm{CD}$ of ionic species or lattice defects in the oxide. However, the donor density in Fig. 13 and the exchange CD of the $\mathrm{Fe}^{3+} / \mathrm{Fe}^{2+}$ redox couple in Fig. 15B are related to the defects in the electronic states. Although the relationship between the lattice and electronic defects should be examined in more detail, it can be suggested that both lattice and electronic state defects decrease with the enrichment of $\mathrm{Cr}$ and $\mathrm{O}^{2-}$ in the passive oxide during constant potential aging.

\section{Conclusions}

The passive oxide film on SUS 304 stainless steel (SS) was studied in a $0.1 \mathrm{~mol} \mathrm{dm}^{-3}(\mathrm{M})$ sulfuric acid solution using ellipsometry, XPS, Mott-Schottky plots, and current measurements of the $\mathrm{Fe}^{3+} / \mathrm{Fe}^{2+}$ redox couple.

(1) The $\mathrm{Cr}$ component was enriched to $57 \mathrm{~mol} \%$ in the passive oxide film, and $\mathrm{Cr}$ and $\mathrm{OH}^{-}$were more distributed in the outer portion of the oxide film than in the inner portion.

(2) During aging of the passive oxide at $0.6 \mathrm{~V}$ for $43 \mathrm{ks}$, the current decreased from $30 \mu \mathrm{A} \mathrm{cm}^{-2}$ at $10 \mathrm{~s}$ to $0.025 \mu \mathrm{A} \mathrm{cm}^{-2}$ at 43 $\mathrm{ks}$ and the $\mathrm{Cr}$ ratio in the passive oxide film simultaneously increased from $49 \mathrm{~mol} \%$ to $57 \mathrm{~mol} \%$, which was accompanied by an increase in the $\mathrm{O}^{2-}$ ratio relative to $\mathrm{OH}^{-}$. The film thickness remained nearly constant at $1.3 \mathrm{~nm}$ during the aging process.

(3) With the enrichment of $\mathrm{Cr}$ and $\mathrm{O}^{2-}$ in the passive oxide film during the aging, the donor density of the n-type semiconducting passive oxide decreased from $4.5 \times 10^{20} \mathrm{~cm}^{-3}$ at $10 \mathrm{~s}$ to $3.5 \times$ $10^{20} \mathrm{~cm}^{-3}$ at $2-43 \mathrm{ks}$, and the exchange current of the $\mathrm{Fe}^{3+} / \mathrm{Fe}^{2+}$ redox reaction on the passive oxide decreased from $1.2 \mu \mathrm{A} \mathrm{cm}^{-2}$ at $10 \mathrm{~s}$ to $0.15 \mu \mathrm{A} \mathrm{cm}^{-2}$ at $22 \mathrm{ks}$.

(4) The possible origin of the $\mathrm{Cr}$ enrichment in the passive oxide film was discussed from a preferential dissolution of $\mathrm{Fe}$ and $\mathrm{Ni}$ relative to $\mathrm{Cr}$.

\section{References}

1. S. Fujimoto, T. Yamada, and T. Shibata, J. Electrochem. Soc., 145, L79 (1998).

2. I. Olefjord, Materials Sci. and Eng., 42, 161 (1980).

3. V. Maurice, W. P. Yang, and P. Marcus, J. Electrochem. Soc., 145, 909 (1998).

4. G. Lorang, M. Da Cunha Belo, A. M. P. Simões, and M. G. S. Ferreira, J. Electrochem. Soc., 141, 3347 (1994).

5. N. E. Hakiki, M. Da Cunha Belo, A. M. P. Simões, and M. G. S. Ferreira, J. Electrochem. Soc., 145, 3821 (1998)

6. M. J. Carmezim, A. M. Simoes, M. F. Montemor, and M. da Cunha Belo, Corros. Sci., 47, 581 (2005).

7. S. Matsuda, K. Sugimoto, and Y. Sawada, Transact. JIM, 18, 66 (1977).

8. K. Sugimoto and S. Matsuda, Mater. Sci. Eng., 42, 181 (1990).

9. S. V. Phadnis, M. K. Toniani, and D. Bhattachaya, Transact. Inst. Metal. Finish. 76, 235 (1998).

10. A. Di Paola, Electrochim. Acta, 34, 203 (1989).

11. A. M. P. Simoes, M. G. S. Ferreira, B. Rondot, and M. da Cunha Belo, J. Electrochem. Soc., 137, 82 (1990).

12. A. M. P. Simoes, M. G. S. Ferreira, B. Rondot, and M. da Cunha Belo, Electrochim. Acta, 36, 315 (1991).

13. R. Babic and M. Metikos-Hukovic, J. Electroanal. Chem., 358, 143 (1993). 
14. J.-P. Petit, A. Antoni, and B. Baroux, European Federation of Corrosion Publication, No. 12, Modifications of passive films, Ed. By P. Marcus, B. Baroux, and M. Keddam, The Institute of Metals (1994) 9.

15. T. L. Sudesh, L. Wijesinghe, and D. J. Blackwood, Corros. Sci., 50, 23 (2008).

16. A. Di Paola, D. Shukla, and U. Stimming, Electrochim. Acta, 36, 345 (1991).

17. M. G. S. Ferreira, A. M. P. Simoes, C. Compere, B. Rondot, and M. da Cunha Belo, Materials Sci. Forum, 289-292, 887 (1998).

18. M. G. S. Ferreira, N. E. Hakiki, G. Goodlet, S. Faty, A. M. P. Simões, and M. da Cunha Belo, Electrochim. Acta, 46, 3767 (2001)

19. L. Freire, M. J. Carmezim, M. G. S. Ferreira, and M. F. Montemor, Electrochim Acta, 55, 6174 (2010)

20. T. Ohtsuka, Y. Sasaki, and A. Hyono, Electrochim. Acta, 60, 384 (2012).

21. K. Asami, K. Hashimoto, and S. Shimodaira, Corros. Sci., 18, 151 (1978).

22. G. Hultquist, M. Seo, T. Leitbner, C. Leigraf, and N. Sato, Corros. Sci., 27, 937 (1987).

23. R. Kirchheim, B. Heine, H. Fischmesiter, S. Hofmann, H. Knote, and U. Stolz, Corros. Sci., 29, 899 (1989).

24. V. Maurice, W. P. Yang, and P. Marcus, J. Electrochem. Soc., 143, 1182 (1996).
25. M. Legrand, B. Diawara, J.-J. Legenfre, and P. Marcus, Corros. Sci., 44, 773 (2002)

26. W. P. Yang, D. Costa, and P. Marcus, J. Electrochem. Soc., 141, 111 (1994).

27. E. McCafferty, Corros. Sci., 42, 1993 (2000).

28. E. McCafferty, Corros. Sci., 44, 1393 (2002).

29. S. Qian, R. C. Newman, R. A. Cottis, and K. Sieradzki, J. Electrochem. Soc., 137, 435 (1990).

30. R. Kirchheim, Electrochim. Acta, 32, 1619 (1987).

31. K. Asami and K. Hashimoto, Corros. Sci., 17, 559 (1977).

32. A. S. Lim and A. Atrens, Appl. Phys., A54, 270 (1992).

33. S. Fujimoto, W.-S. Kim, M. Sato, J.-Y. Son, M. Machida, and H. Tsuchiya, J. Sol. State Electrochem., 19, 3521 (2015).

34. R.-H. Jung, Y. Tsuchiya, and S. Fujimoto, Corros. Sci., 58, 62 (2012).

35. C. Donic, A. Kocijan, D. Mandrino, and M. Jenko, Metallurgy and Materials Transact. B, 42, 1044 (2011).

36. K. Asami and K. Hashimoto, Corros. Sci., 45, 2263 (2003).

37. T. Ohtsuka, M. Abe, and T. Ishii, J. Electrochem. Soc., 162, C528 (2015)

38. H. Cabrera and N. F. Mott, Rep. Prog. Phys., 12, 163 (1948).

39. N. F. Mott, Trans. Faraday Soc., 43, 429 (1947). 